TERRA. Revista de Desarrollo Local e-ISSN: 2386-9968

Número 9 (2021), 122-146

DOI 10.7203/terra.9.21761

IIDL - Instituto Interuniversitario de Desarrollo Local

\title{
Ruptura Urbana. Las relaciones entre la morfología urbana y la estructura social de L'Hospitalet de Llobregat (Barcelona, España)
}

\author{
Alejandro Caamaño López \\ Dr. en Sociología. Ldo. en Ciencias Políticas y Administración por la Universidad de \\ Barcelona \\ alejandrocaamanho@gmail.com
}

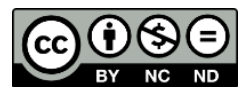

Esta obra se distribuye con la licencia Creative Commons Reconocimiento-No Comercial-Sin Obra Derivada 4.0 Internacional 


\title{
SECCIÓN NOTAS Y AVANCES DE INVESTIGACIÓN
}

\author{
Ruptura Urbana. Las relaciones entre la morfología urbana y la estructura social de L'Hospitalet \\ de Llobregat (Barcelona, España)
}

Resumen: L'Hospitalet de Llobregat continúa afrontando proyectos urbanísticos de grandes dimensiones, como la segunda fase del Plan de Dirección Urbanística Gran Vía -PDU Gran Vía-, con una inversión pública prevista de 150 millones; la configuración de Santa Eulàlia Avenue; y la proliferación de HUTs alrededor de toda la ciudad en los últimos años, o la creación del Plan de Distrito Cultural de perímetro abierto. La aparición de grandes inversiones urbanísticas y grandes cambios que ha afrontado la ciudad, generando una gran dualidad entre las zonas de Collblanc-La Torrasa, Florida-Les Planes o Pubilla Cases como eje norte de la ciudad en relación a la zona sur en la que se concentran gran parte de estos nuevos procesos urbanísticos, obliga a plantearse la distribución de la población en la ciudad según niveles de renta mediante procesos de migración forzosa y selectiva intramunicipales y extramunicipales. Examinando este caso podemos observar el aumento de la segregación residencial socioeconómica en relación al aumento del precio del alquiler y suelo e identificar los factores que explican las pautas de estructuración socioresidencial durante este periodo mediante un proceso de sistematización bibliográfica y fuentes secundarias junto un análisis cualitativo de observación directa y entrevistas a los diversos actores implicados en la ciudad.

Palabras clave: L'Hospitalet de Llobregat; ruptura urbana; migración; morfologia urbana.

\section{Urban Rupture. Relations between urban morphology and social structure in L'Hospitalet de Llobregat (Barcelona, Spain)}

\begin{abstract}
L'Hospitalet de Llobregat continues to face large-scale town projects, such as the second phase of the Gran Vía Urban Planning Plan -PDU Gran Vía-, with a planned public investment of 150 million; the configuration of Santa Eulàlia Avenue; and the proliferation of HUTs around the city in recent years, or the creation of the Cultural District Plan with open perimeter. The emergence of big urban investments and big changes that the city has faced, generating a great duality between the areas of Collblanc-La Torrasa, Florida-Les Planes or Pubilla Cases as the north axis of the city in relation to the southern area in which most of these new urban processes are concentrated, forces us to consider the distribution of the population in the city according to income levels through forced and selective migration processes intra-municipal and extra-municipal. Examining this case, we can observe the increase in socioeconomic residential segregation in relation to the increase in the price of rent and land and identify the factors that explain the patterns of the socio-residential structuring during this period through a process of bibliographic systematization and secondary sources together with a qualitative analysis of direct observation and interviews with the various actors involved in the city.
\end{abstract}

Key words: L'Hospitalet de Llobregat; urban disruption; migration; urban morphology.

Recibido: 15 de octubre de 2021

Devuelto para revisión: 16 de diciembre de 2021

Aceptado: 26 de diciembre de 2021

\section{Referencia / Citation:}

Caamaño, A. (2021). Ruptura urbana. Las relaciones entre la morfología urbana y la estructura social de L'Hospitalet de Llobregat (Barcelona, España). TERRA. Revista de Desarrollo Local, (9), 122-146. DOI 10.7203/terra.9.21761 


\section{INTRODUCCIÓN}

La Ciudad de la Justicia y la plaza de Europa son para la mayoría de barceloneses el único contacto vivido con L'Hospitalet de Llobregat, una frontera y espacio de servicios compartidos con el municipio de Barcelona. L'Hospitalet de Llobregat es también la sede del Mobile World Congress, pero también encontramos algunos de los polígonos de vivienda social más empobrecidos del país, como los Bloques Florida, donde nos encontramos con la densificación poblacional más elevada de Europa ${ }^{1}$ y la segunda del mundo con $74.205 \mathrm{hab} / \mathrm{km}^{2}$; o zonas de uso agrícola como Cal Trabal; los últimos restos de la historia agrícola de la ciudad.

L'Hospitalet de Llobregat, deviene a su vez el segundo municipio más poblado de Cataluña con un total de 261.068 habitantes y la densidad más alta de Europa con 53.119 $\mathrm{hab} / \mathrm{km}^{2}$. Una ciudad de carácter complejo y diverso que ha experimentado una incuestionable y enorme transformación en términos urbanísticos con un entramado de grandes empresas que se han instalado a raíz de la multimillonaria inversión pública abocada a la reforma de la Gran Vía y la creación de la plaza de Europa.

Partimos entonces de un análisis teórico y empírico del trabajo de Bonal y Costa y un estudio detallado del debate entre Lefebvre y Castells que recupera los estudios urbanos sobre la producción del espacio, la división social del mismo y sus rupturas urbanas en L'Hospitalet de Llobregat (Morcuende, 2016). Teniendo como objeto de estudio las principales reformas urbanísticas de la ciudad pasando desde la reforma de la Gran Vía y la creación de la plaza de Europa hasta la configuración del Distrito Cultural y Santa Eulàlia Avenue para determinar en qué sentido estos llegan a incidir el aumento de la segregación residencial.

\section{METODOLOGÍA}

Para la realización de este trabajo partiremos de la revisión y selección de referencias bibliográficas relativas al estudio del desarrollo urbano contemporáneo y en específico en el Estado Español y L'Hospitalet de Llobregat, que aporten datos tanto cualitativos como cuantitativos que nos permitan realizar un análisis sistemático para ofrecer una investigación con mayor rigurosidad metodológica respecto el análisis de datos y su sistematización; así como para velar por una selección pertinente de documentos que nos permita permeabilizar la elaboración del estudio de una manera fundamentada que eluda sesgos en la identificación y en el empleo de información (Sánchez; Botella, 2010).

En concreto nos centraremos en los estudios e información relativa a la Plaza Europa, el proyecto urbanístico del PDU Gran Vía, el Distrito Económico y el Distrito Cultural.

Posteriormente utilizaremos el método de observación directa como herramienta en el presente estudio, mediante el cual se logra el conocimiento del entorno cotidiano (Lefebvre, 1974) y la familiarización con el espacio físico, en el cual se integran con la observación participante del investigador como ciudadano y activista de la ciudad desde 2015. El registro de datos obtenidos en un cuaderno de campo que especifica las características morfológicas de los diversos espacios, su uso -Comercial; Industrial;

\footnotetext{
${ }^{1}$ Eurostat. Urban Europe. Statistics on cities, towns and suburbs. Life in cities. 2016.
} 
Residencial o de Tránsito-, la tendencia habitacional -Propiedad; Alquiler u Otras- y la estructura social que configura, así como también percepciones personales.

A su vez procederemos al análisis de entrevistas no estructuradas en profundidad dirigidas a actores de la sociedad civil y del ámbito de gestión pública. Incluyendo en él usuarios, residentes, agentes sociales y activistas y profesionales involucrados (Cuadro $\mathrm{N}^{\circ} 1$ ) en la gestión de las instituciones públicas con tal de recoger información sobre la planificación, actuaciones, experiencias, expectativas y visiones de los diversos agentes entrevistados tanto en el análisis y respuestas relativas a los procesos de remodelación urbanística y los procesos migratorios que estos implican.

Para completar el análisis se cotejan y analiza la información recopilada durante el trabajo de investigación. Interpretaremos los datos obtenidos junto a una comparativa histórica de los procesos migratorios dados en los últimos 20 años para comprender el diálogo establecido entre el espacio planificado y el espacio vivido de los espacios estudiados. Desarrollaremos la investigación en el marco de la metodología cualitativa y el estudio e interpretación de las entrevistas en profundidad mediante el método de análisis cualitativo Grounded Theory de Strauss y Corbin (2002).

Tabla 1. Número y tipo de actores entrevistados

\begin{tabular}{|c|c|}
\hline Sociedad Civil & (15) \\
\hline Residentes & 10 \\
\hline Activistas y Trabajadoras Sociales & 5 \\
\hline Representantes Institucionales & 2 \\
\hline
\end{tabular}

Fuente: elaboración propia.

\section{RESULTADOS}

\subsection{La Plaza de Europa}

La plaza Europa constituye el epicentro económico de L'Hospitalet de Llobregat; ocupa una superficie de 32.000 metros cuadrados, y observamos un espacio público de la zona con escaso tránsito y con todavía menos peatones siendo prácticamente desierto su uso. Desde su inauguración en 2007, ha acontecido el núcleo de una nueva centralidad económica de la gran Barcelona Metropolitana.

En apenas unos centenares de metros se concentran dos grandes superficies comerciales que suponen el centro Gran Vía 2 e Ikea, junto a la diversidad corporativa de grandes marcas empresariales como KPMG, Werfen, Gallina Blanca, Pfizer, Copisa, Olympus, Acciona o Nissan Motor Ibérica; junto a trece grandes hoteles como Renaissance Barcelona Feria o el Hotel Trae Feria y, obviamente, las instalaciones de la Feria de Barcelona, epicentro del Mobile World Congress.

La transformación que hizo posible la creación de la plaza de Europa la lideró el Consorcio para la Reforma de la Gran Vía, constituido el 2002 por el Ayuntamiento de L'Hospitalet de Llobregat y la Generalitat de Catalunya. La primera fase de la transformación del eje supuso una inversión de 285 millones. 
El espacio es el gran nodo de atracción de negocios de la ciudad y según la información aportada por la alcaldesa de la ciudad, la Sra. Núria Marín, las empresas instaladas al Distrito Económico aportan 18 millones de euros anuales a las arcas municipales y estos recursos "han permitido salir adelante proyectos tan relevantes como el polideportivo del Gornal, Torre Barrina, el cine Romero, la escuela de música y el equipamiento de los Bloques Florida"2.

Una vecina del barrio de Santa Eulàlia nos relata:

\begin{abstract}
“Ocasionalmente utilizo el espacio para pasear al perro cuando voy sola, ya que, aunque no esté habilitado, no suele haber gente y hay muy pocos espacios donde poder soltar al perro y ninguno que permita compaginar con parques infantiles cuando estoy con la familia. Aun así, no suele haber mucha vida, la gente lo utiliza como un sitio de paso por la estación de metro y ferrocarril para ir al Gran Vía 2 o al IKEA; pero sobretodo los coches que salen de la autopista para ir a trabajar o volver del trabajo".
\end{abstract}

No obstante, podemos constatar como el desarrollo comercial del centro Gran Vía 2 e Ikea cronifica la existencia de una ciudad de dos velocidades, según explica la técnica del proyecto comunitario de inclusión social impulsado por la ABD, Comunitat Activa, y responsable de soporte a la familia y Participación Comunitaria, Ana Anguita; con claros desequilibrios entre barrios y zonas, como Pubilla-Cases, Florida-Les Planes o CollblancLa Torrassa donde este supuesto beneficio atribuido en diversas conferencias y declaraciones del Partido Socialista en tanto su connotación social, no ha tenido concreciones materiales sobre el bienestar de los vecinos, donde radica una mayor concentración poblacional y tasas de residentes migrados con una renta un $23 \%$ por debajo de las zonas más ricas ubicadas en el eje Gran Via Sud ${ }^{3}$; mientras podemos constatar un aumento del precio del alquiler medio en Hospitalet de Llobregat de un 13\% entre 2001 y 2002, año de inauguración del centro Gran Vía 2.

Una cifra que se acentúa en los distritos Santa Eulàlia y Gran Vía Sud ${ }^{4}$ generando una división respecto al resto de la zona sud con un $11,8 \%$ de diferencia en el precio medio del alquiler, y posteriormente con una mayor diferencia en la zona norte del $18 \%$ con salvedad de Collblanc, con un $14 \%$ de diferencia; una media dos puntos superior a la catalana en los mismos años y de casi un $3 \%$ respecto Barcelona ${ }^{5}$; unos resultados muy similares a los ofrecidos por Idescat relativos al precio de la vivienda.

Del mismo modo intuimos un proceso de movilidad interna y externa hacia las zonas periféricas por parte de los residentes previos de las áreas coetáneas a estos centros junto una renovación socioeconómica de Santa Eulàlia tal como relata el Presidente del Centro de Estudios de L'Hospitalet y vecino de la zona desde los años noventa, que relata la existencia de:

\footnotetext{
"un proceso en el que se conjugaba un incremento del precio de la vivienda en plena burbuja inmobiliaria y un uso substitutivo del espacio que atravesaba toda la ciudad, pero un incremento mayor en la zona por las expectativas especulativas que ofrecían Gran Vía 2 e IKEA, duplicando el número de pisos y suelo urbanizado en un corto periodo de tiempo; si bien es cierto que los beneficios que ello suponía no han sido percibidos por los vecinos del distrito".
}

\footnotetext{
${ }^{2}$ Entrevista para El Punt Avui. El feu socialista s'esquerda. 2015.

${ }^{3}$ Agencia Tributaria. Renta bruta y Renta disponible inframunicipal. 2016.

${ }^{4}$ SIG Gencat.

${ }^{5}$ Idescat. Alquiler de viviendas. Rentas medias mensuales. Municipios con más de 70.000 habitantes.
} 
En la zona se concentran buena parte de los 13 hoteles con un total de 3.500 plazas de las que dispone la ciudad. Mientras que el gobierno barcelonés de Ada Colau ha llegado a la conclusión que hay que racionalizar y reducir progresivamente la presión hotelera en las zonas más densificadas de la capital, el equipo de Marín apuesta justo por el contrario llegando a firmar un acuerdo con el Gremio de Hoteles de Barcelona para implantar nuevos establecimientos en la ciudad. La apuesta hotelera es sólo una de las patas del supuesto desarrollo económico que promueve el gobierno del PSC. En enero del año pasado se presentó el Plano Director Urbanístico -PDU- Gran Vía-Llobregat, que prevé la transformación de 994.000 metros cuadrados de suelo, el $8 \%$ del término municipal. El proyecto supone la segunda fase de la reforma de la Gran Vía y, a la práctica, implica la conexión de la plaza de Europa con el río Llobregat; la creación del parque de Cal Trabal, de 27,9 hectáreas en Bellvitge; el impulso del clúster de investigación biomédica y la transformación del último tramo de la Gran Vía en una vía urbana. Se calcula que las obras, que aún no tienen fecha de inicio, supondrán una inversión de 150 millones por parte del consorcio público.

\subsection{El Distrito Cultural}

En la zona colindante de Cobalto encontramos el denominado futuro 'Central Street' del Distrito Cultural, un ambiente de no-lugar metropolitano (Auge, 2009) compuesto por una morfología de naves industriales en gran porcentaje abandonadas y recintos fabriles, ubicado a escaso kilómetro de distancia de la plaza de Europa, el cual pretende devenir en un proceso de ocho años hasta 2025, según el Ayuntamiento encabezado por Núria Marín, y con una inversión 30 millones de euros -cofinanciados por la UE- pretende devenir un polo de actividad cultural. No obstante, Núria Marín afirma que, si Europa no aporta nada, será el consistorio quién asumirá todo el gasto ${ }^{6}$. De momento, el presupuesto de 2016 sólo incluye una partida de $86.000 €$ destinada al Distrito Cultural como perímetro abierto sin proyecto urbanístico o social definidos como tales.

El proyecto, ideado y dirigido por el exdirector general del Gran Teatro del Liceo Joan Francesc Marco, en el filósofo y exdirector del CCCB Josep Ramoneda, ayudaba en su construcción pronunciándose en abril de 2013 con diversas propuestas en el ámbito de la cultura para L'Hospitalet ${ }^{7}$, se describe en su propia página web como:

\footnotetext{
"un proyecto estratégico de ciudad que tiene la cultura como motor de transformación y de crecimiento social y económico, para convertir L’Hospitalet en una ciudad líder del área metropolitana donde la creatividad, el talento y la innovación son los protagonistas. Una apuesta para que los sectores culturales y creativos dinamicen la ciudad y mejoren la calidad de vida de las personas. Un espacio en constante transformación, donde trabajan y conviven creadores, emprendedores, artistas y ciudadanos" $"$.
}

A día de hoy el proyecto cuenta 500 agentes, que se suman a los más de 30 equipamientos producidos en la ciudad con motivo de desarrollar el proyecto, por demás de los espacios de restauración y cocina creativa, y otros espacios que nos obligan a observar la incidencia material en que se produce una transformación urbanística del territorio.

\footnotetext{
${ }^{6}$ Conferencia anual sobre proyectos estratégicos para L'Hospitalet. 2016.

${ }^{7}$ L'Hospitalet i la cultura. Una visió impressionista i algunes propostes.

${ }^{8}$ www.lhdistrictecultural.cat
} 
Este proyecto es fuertemente contestado por activistas culturales de base de la ciudad, con el argumento que, como en otras cuestiones, se basa en "una lógica exclusivamente comercial y no en una función o lógica social"; sin atender las necesidades y demandas de los habitantes, según explica el activista y artista local, Víctor Gómez. El teórico nuevo distrito dispone de unas 25 hectáreas en una zona industrial, con algunas naves donde todavía hay actividad y muchas que acumulan años cerradas. El proyecto, promovido en medios tradicionales como un futuro polo de atracción de la ciudad, ya ha permitido la llegada de algunos artistas a la zona, provenientes de Barcelona, donde tenían que afrontar alquileres mucho más elevados. De hecho, uno de los atractivos es la fiscalidad, puesto que el consistorio ha decidido bonificar al $95 \%$ el impuesto de bienes inmuebles y el impuesto de actividades económicas -IAE- a todas las empresas culturales que se instalen a partir de este año.

Con tal de buscar legitimación, el ayuntamiento de L'Hospitalet de Llobregat decidió convocar un proceso participativo en 2013 para pensar el futuro de la ciudad y acerca de cómo se debería transformar L'Hospitalet de cara al año 2025, el centenario del año en el que se le otorgó el título de ciudad: L’H On.

Un proceso con una escasa participación de apenas 7.200 personas, un reducido $2 \%$ de la población de L'Hospitalet, que lleva a Francisco Rubio, miembro de la cooperativa La Fundició, que impulsa procesos colectivos de construcción de conocimiento y prácticas culturales, a afirmar que el "proyecto participativo ligado al Distrito Cultural era una falacia. La participación no existía, pero querían vender que era una reivindicación ciudadana". Por su parte, el regidor de la candidatura CUP-Poble Actiu, Khristian Giménez, apunta a la "sensación de que legitiman el Distrito Cultural porque necesitan tener otro modelo después de que la vía de financiar el Ayuntamiento a través de la cultura del ladrillo se convierta en insostenible. Se tienen que inventar una salida nueva y creen que la podrán conseguir con este nuevo proyecto", y este deviene en primera instancia una imitación del modelo cultural de Brooklyn ${ }^{9}$ que apunta en su realización a un aumento del suelo de las zonas colindantes desde Hospitalet Centro a Bellvitge.

Dadas las similitudes que se expresan con el desarrollo de Brooklyn; deviene necesario atender a las aportaciones de Manuel Castells (1972) sobre las operaciones de rehabilitación y renovación que se llevaron a cabo en diversos barrios parisinos entre 1955 y 1970, y sobre las que planteaba una consecuencia directa sobre el cambio de la ocupación social del espacio en la posición céntrica y la transformación funcional de los mismos, acentuando la segregación residencial mediante el aumento de presencia de los estratos adquisitivos superiores en la ciudad mientras, desplazando las clases populares hacia la periferia, observando que el Distrito Cultural de L'Hospitalet está suponiendo un cambio de la ocupación del espacio, del cual su gran mayoría está actualmente en desuso; su posición céntrica en la ciudad y la transformación funcional de la zona prevista que obliga a considerar la posibilidad de que el Distrito en un estadio más avanzado pueda gentrificar la zona al sumarse las actual definición elaborada por el Col·legi d'Enginyers de Camins, Canals i Ports de Catalunya tratándose de un proceso dado:

\footnotetext{
“cuando en los barrios populares y más baratos empieza a instalarse gente con un poder adquisitivo más alto. Esto hace que se inicie un periodo de restauración y mejora de las calles y los edificios de manera que aumenta el valor y el precio en la zona, tanto a nivel inmobiliario como a nivel de comercios, restaurantes y servicios en general. Estas modificaciones urbanísticas, además, provocan
}

\footnotetext{
${ }^{9}$ Intervención de Dña. Núria Marín en la reunión de la Red Global de Distritos Culturales. 2016.
} 
una completa transformación social, cultural y económica que cambia de raíz el tejido del barrio en el que se produce el fenómeno"10.

Aquí es necesario analizar el comportamiento del capital inmobiliario y del mercado del suelo y el cambio de las ciudades hacia una economía basada en los servicios, según el sociólogo y Doctor en Políticas Públicas y Transformación Social, Marc Martí Costa (2012), para poder entender las dinámicas desplegadas y las alertas futuras que suscita la zona observando la aparición de nuevas construcciones de vivienda de la constructora Nuñez y Navarro en las zonas colindantes de Cobalto, así como la acomodación de la zona mediante la construcción de nuevos espacios como Mercadona en la antigua Sala Salamandra 2.

\subsection{Santa Eulàlia Avenue}

En plena carretera Santa Eulàlia, una de las arterias que comunica con Barcelona y a su vez genera una de las principales divisorias físicas y administrativas con la zona norte del municipio en el segundo distrito más rico de la ciudad detrás de Centre-San Josep ${ }^{11}$, nos encontramos con la promoción inmobiliaria Santa Eulàlia Avenue; una promoción de nueva obra que abarca un conjunto de seis grandes bloques de aproximadamente seis plantas cada uno con plantas bajas destinadas a comercios y servicios que comprende el último tramo de la carretera rodeando el recinto destinado al polideportivo de Santa Eulàlia aún sin edificar, donde radica una gran zona de parking informal, y la histórica fábrica de Can Trinxet, inaugurada 1910, que se encuentra actualmente en una clara situación de detrimento y degradación ante una actitud de pasividad del Ayuntamiento que según declara el regidor del Distrito carece de proyecto de futuro planteado por la administración más allá del vallado en actual construcción con los fondos de AMB destinados a la restauración y conservación del patrimonio de $119.926,97 €^{12}$.

Según narra el historiador y vecino, Manuel Domínguez:

“es la mayor pérdida generada de patrimonio histórico en la ciudad y, en comparación a antiguas fábricas de la ciudad como la existente en la actual plaza Milagros Consernau; la que ha sufrido un proceso de edificación más densa en comparación; cercando prácticamente el total del espacio que la fábrica ocupaba”.

La plataforma de entidades de la ciudad Can Trinxet Viu, señala que esta situación no se puede entender sin contextualizarla en un modelo de producción urbanística concreto en la ciudad, señalando que "el modelo de ciudad que se está imponiendo favorece la privatización de nuestros barrios con la creación de distritos económicos o culturales; permitiendo la especulación que ha llevado a unos precios de las viviendas de alquiler inasequibles y debilitando el movimiento asociativo"13. Apuntando a la necesidad de contextualizar el deterioro y abandono de la fábrica en una ubicación geográfica donde

\footnotetext{
${ }^{10} \mathrm{Col} \cdot$ legi d'enginyers de Camins, Canals i Ports. Gentrificació: causes i conseqüències. 2015.

${ }^{11}$ Agencia Tributaria. Renta bruta y Renta disponible inframunicipal. 2016.

${ }^{12}$ Contractaciopublica.gencat.cat. Obres per a la construcció del nou tancament a Can Trinxet al terme municipal de l'Hospitalet de Llobregat.

${ }^{13}$ Cantrinxetviu.wordpress.com
} 
desde 2017 se encuentran a la venta un seguido de viviendas que se promocionan con el enaltecimiento de la exclusividad ${ }^{14}$ generando una clara disrupción y discontinuidad con la urbanización y construcción clásica de la carretera con un precio medio de $2.284 € \mathrm{~m} 2$; un $44 \%$ más que el precio original de la vivienda en $2015^{15}$ de $1.584,25 € \mathrm{~m} 2$ y un $39 \%$ respecto los $1.634 € \mathrm{~m} 2$ en 2016.

\subsection{Sobre la «gentrificación» y el aumento de HUTs}

Sumado a las anteriores reflexiones relativas al Distrito Cultural, debe tenerse en cuenta que el documento de conclusiones de L'H On resulta explícito sobre el papel que debe que tener la cultura al afirmar que:

\footnotetext{
"nos tenemos que plantear el reto de la gestión de la cultura como servicio público irrenunciable, pero al mismo tiempo como una actividad que participa en una economía de mercado y sobre todo en la formalización de una relación proactiva que reconozca su papel en la nueva economía desde la perspectiva de las industrias creativas y de la capacidad de dotarlas de una gobernanza integral propia. No se trata de mercantilizar la cultura sino de humanizar la economía"16.
}

Según una de los activistas consultados, la traducción es clara: "será en la medida que la empresa privada pueda funcionar bien que habrá cultura. Su tesis es que sólo habrá un regreso social si la vía privada funciona bien".

Las personas consultadas son muy críticas con la política cultural que históricamente ha llevado a cabo el consistorio y alertan que puede comportar problemas de gentrificación en la zona, es decir, la progresiva expulsión de los vecinos tradicionales por nuevos habitantes atraídos por la elitización del barrio; un proceso contrastable en zonas como el Distrito Económico y la Plaza Europa; así como inclusive a las zonas norte con una conexión directa al municipio de Barcelona, donde la construcción y proliferación de Viviendas de Uso Turístico ha proliferado en 2017 hasta un total de 151 pisos con licencia alrededor de L'Hospitalet de Llobregat, principalmente concentrados en la zona de Collblanc y Santa Eulàlia; por demás de las licencias de apartamentos turísticos sumando más de 300 apartamentos según revela la página de Airbnb, sin especificar la cantidad exacta de pisos que radican en L'Hospitalet, pero apuntando según La Vanguardia, a un aumento del $63 \%{ }^{17}$ en 2017 respecto al año anterior, un registro que oscila entre 500 viviendas de forma aproximada ${ }^{18}$. Todo esto genera un aumento del precio medio del alquiler estimado en el $54,4 \%$ en los últimos cuatro años ${ }^{19}$ que produce un aumento en el coste de las viviendas, siendo actualmente de un total de $20.164 €$ anuales, la renta familiar disponible de L'Hospitalet de Llobregat, en comparación a los $28.908 €$ del Área Metropolitana de Barcelona y los 27.226€ de Cataluña.

Destacando a su vez que pese analizar el subconjunto de L'Hospitalet, dentro de una ciudad tan pequeña nos encontramos con disparidades entre distritos que van desde

\footnotetext{
${ }^{14}$ Corp-promotores.es

${ }^{15}$ SIG Gencat

${ }^{16} \mathrm{~L}$ 'H on. El futur per endavant. Página 9.

${ }^{17}$ La proliferación de pisos turísticos se extiende al extrarradio barcelonés. 8 de Agosto de 2017.

${ }^{18}$ Mapa ¿Cuántas viviendas de tu barrio están en Airbnb? de Eldiario.es a septiembre 2018.

${ }^{19}$ Idealista.es
} 
$22.275 €$ en San Josep - Centro a $17.747 €$ en el distrito de Florida o 18,793€ en Pubilla Cases.

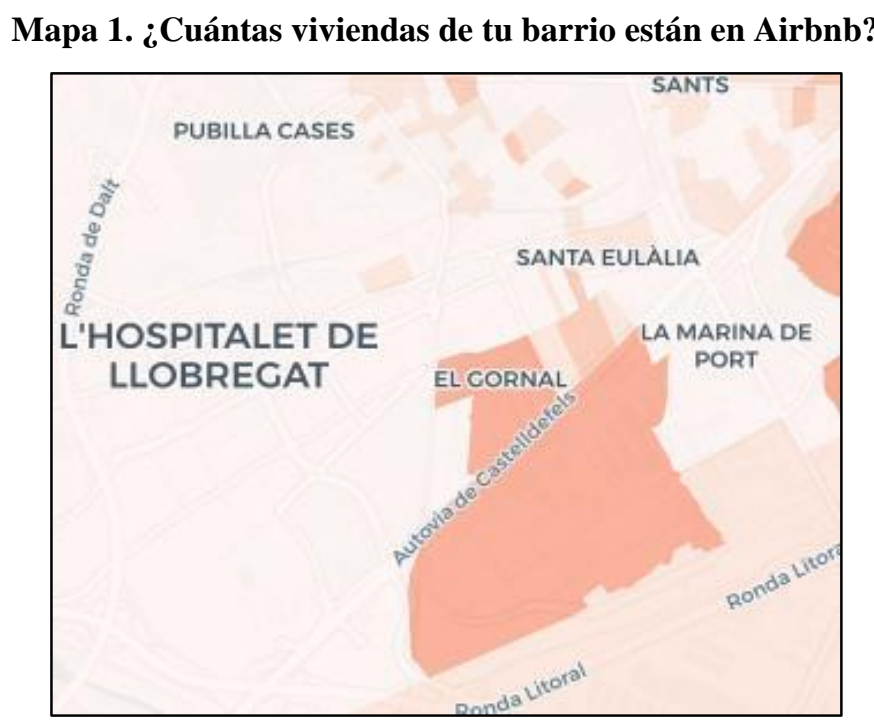

Fuente: Eldiario.es a septiembre 2018

\subsection{Cal Trabal}

Para completar el retrato de la ciudad, reseguimos la Gran Vía poco más de tres kilómetros en dirección al río, y la imagen es radicalmente diferente respecto de la plaza de Europa. En Can Trabal, epicentro del último espacio agrícola de la ciudad y emblema de una lucha ciudadana para garantizar la preservación del medio ambiente aún no existe presencia de torres, únicamente tres masías. Cal Trabal, Can l'Esquerrer y Can Masover Nou.

El nuevo proyecto de transformación de la Gran Vía, que se consolida como segunda fase de la reforma iniciada a principios del siglo XXI con la construcción de la plaza de Europa como principal exponente, amenaza el entorno, extendiéndose por un $8 \%$ del territorio que supone el último vestigio de zona agrícola en la ciudad y, a su vez, supone el principal pulmón de la ciudad. Un plan que, según denuncian las vecinas que configuran la asamblea No més blocs/ Salvem L'Hospitalet desde 2015, se produce sin ningún tipo de consulta entorno las necesidades de la ciudad ${ }^{20}$ y se enfoca como una extensión de Barcelona.

El PDU prevé la construcción de nueve torres de gran altura, hecho que ha motivado la presentación de diversas a alegaciones por parte de entidades ecologistas, culturales y vecinales, para reclamar que se mantenga como zona agrícola, y no sea únicamente zona verde, existiendo diversas movilizaciones vecinales contra el PDU, de las que podemos destacar las encabezadas por la plataforma Salvem Cal Trabal, que rechaza la construcción de 26 grandes edificios que prevé el PDU y considera que el proyecto repite los vicios del modelo especulativo de la época de la burbuja, con una apuesta clara por la economía del ladrillo.

${ }^{20}$ Nomesblocs.wordpress.com 
A pesar de ubicarse a escasa distancia de la autovía A-2 y de las rondas de Dalt y del Litoral, Cal Trabal es una estampa que evoca el pasado agrario de la zona, cuando todavía faltaban muchas décadas para la urbanización acelerada a golpe de cemento. A la vez conecta con la visión de futuro de ciudad que impulsa una parte de la ciudadanía, que aboga por la preservación parajes tradicionales y no fiarlo a la construcción y al modelo económico de servicios y cultura que impulsa el Ayuntamiento de L'Hospitalet de Llobregat.

\section{REFLEXIONES}

El modelo de ciudad impulsado por el PSC en L'Hospitalet de Llobregat deviene el único que se ha podido conocer desde las elecciones municipales de 1979. Un modelo que genera un gran impacto sobre la distribución de recursos en el territorio generando una ruptura urbana que plasma una distribución de la ciudad en relación al nivel socioeconómico y una polarización exacerbada entre las proyecciones urbanísticas desarrolladas en la zona sur de la ciudad de L'Hospitalet en contraste a los índices de pobreza, migración y densidad articulados en la zona norte de la ciudad, donde, no obstante, la colindancia con Barcelona que, según Elena Sala en relación a los argumentos expuesto como técnica de Comunitat Activa para la Televisión de L'Hospitalet ${ }^{21}$, ofrece "una ubicación perfecta para empezar a gentrificarnos. Está junto al Camp Nou y hay una buena combinación con el aeropuerto, una zona propicia para la creación de nuevos pisos turísticos"; junto la expansión del impacto en el precio del suelo que se deduce en las zonas directamente afectadas, generan una sobrecarga en los costes de la vivienda en distritos donde supone el principal modelo de vivienda, del 63,67\% frente al 41,16\% del Área Metropolitana o el 46,36\% de Cataluña.

Como consecuencia se produce un proceso de expulsión y renovación paulatina de los núcleos socioeconómicos en la zona que cada vez asumen mayores problemas relativos a la vivienda, deviniendo un proceso forzado de migración selectiva de la población más afectada por la crisis, acentuando la configuración dual de una ciudad que, consolida su zona sur ofreciendo L'Hospitalet de Llobregat como un nuevo Distrito para Barcelona con el desarrollo del DEGV a modo de nuevo Diagonal Sud o 22@ ${ }^{22}$, siendo la operación más relevante de Catalunya en suelo edificable con 1.500.000 m2, después del 22@ con $3.100 .000 \mathrm{~m} 2$, y del Centre Direccional de Cerdanyola con $2.100 .000 \mathrm{~m} 2$; que no tan solo genera una interconectividad necesaria para el desarrollo económico de la Ciudad de Barcelona, sino que consolida la dualidad con profesionales cualificados en las nuevas zonas de la zona comprendida por Gran Vía Sud y migrantes de sin cualificación en el distrito de la Florida, cronificando el detrimento de la zona.

\section{REFERENCIAS}

Anderson, P. (1979). Considerations on Western Marxism. Siglo XXI.

Andreu, M. (2016). Ciutats invisibles. Viatges a la Catalunya metropolitana. L'Avenc.

Arias, F. (2000). Desigualdad urbana en España. Ministerio de Fomento.

${ }^{21}$ La pujada del preus del lloguer expulsa a veïns de Collblanc Torrassa. Televisió de L'Hospitalet.

${ }^{22}$ PRITETO, Montse; MUÑ́́Z, Dominica. L’Hospitalet. Un nou districte per Barcelona. 
Auge, M. (2000). Los no lugares. Antropología sobre la modernidad. Gedisa Editorial.

Bayona, J. (2007). La segregación residencial de la población extranjera en Barcelona. ¿Una segregación fragmentada. Scripta Nova. Revista Electrónica y Ciencias Sociales, 235(11), 1-32.

Bermejo, E. (2018, 10 03). Districte cultural de l'hospitalet: aposta per la creació o per l'especulació? Recuperado de: Directa.cat: https://directa.cat/districte-cultural-delhospitalet-aposta-per-la-creacio-o-per-lespeculacio/ (10/04/2021).

Bettin, G. (1982). Los sociólogos de la ciudad. Gustavo Gili.

Bosch, J. (2008). Integració i mobilitat residencial de la población immigrada a Catalunya. Les condicions de vida de la población immigrada a Catalunya. Fundació Jaume Bofill.

Brenner, N. (2014). Implosions/explosions: Towards a Study of Planetary Urbanitztation. Jovis.

Burbano, F. A. (2013). Las migraciones internas durante el franquismo y sus efectos sociales: el caso de Barcelona. Memoria de investigación. Universidad Complutense de Madrid.

Buzar, S., Ogden, P., y Hall, R. (2005). Households matter: the quiet demography of urban transformation. Progress in Human Geography, (29), 413-436.

Capel, H. (1973). Capitalismo y morfología urbana en España. De la frontera.

Capel, H. (2002). Sociedad, cultura y paisaje urbano. En H. Capel (ed.), La morfología de las ciudades. Ediciones del Serbal.

Carreras, C., Morcuende, A., Martínez Rigol, S., y Lluis, F. (2015). Cities, public space and citizenship: some contemporany mediterranean urban social movements. Annual International Conference on Earth, Geology and Geography. Atenas.

Champion, T. (2001). Handbook of Urban Studies. En T. Champion (ed.), Urbanization, Suburbanization, Counterurbanization and Reurbanization (pp. 143-161). SAGE.

Choay, F. (1994). Urbanization, Suburbanization, Counterurbanization and Reurbanization. In M. A. (ed.), Lo urbano en 20 autores contemporáneos (pp. 61-72). Edicions UPC.

Clark, W. (1983). L'estructura socioespacial de la regió metropolitana de Barcelona des d'una aproximació multimètode. Una proposta metodològica per a l'estudi de la diferenciació socioresidencial. Urban Studies, 20(1), 47-57.

Costa, M., y Sergio, P. (2013). L'estructura socioespacial de la regió metropolitana de Barcelona des d'una aproximació multimètode. Una proposta metodològica per a l'estudi de la diferenciació socioresidencial. Documents d'Anàlisi Geogràfica, 59(2), 315-345.

Engels, F. (1964). Anti-Düring. La Subversión de la ciencia por el sueño Eugen Dühring. Editorial Fondo de Cultura Económica.

Font, M. (2016, 03 22). L'Hospitalet de Llobregat: les ombres de quatre dècades de poder socialista. Recuperado de: http://www.elcritic.cat/investigacio//hospitalet-dellobregat-les-ombres-de-quatre-decades-de-poder-socialista-8693 (10/10/2021).

García, G. (2018, 10 22). El projecte de pisos rusc desobeeix l'ordre de precinte de l'Ajuntament de Barcelona. Recuperado de: https://directa.cat/el-projecte-de-pisos- 
rusc-amenaca-de-resistir-davant-lordre-de-precinte-de-lajuntament-de-barcelona/ $(10 / 10 / 2021)$.

Gasca, J. (2017). Espacios del consumo y el comercio en la ciudad contemporánea. Universidad Nacional Autónoma de México e Instituto de Investigaciones Económicas.

Gilbert, L. (2012). Els joves dominicans de L'Hospitalet i el racisme: una recerca etnográfica. Quaderns d'estudi, (26), 147-176.

Harvey, D. (1977). Urbanismo y Desigualdad Social. Siglo XXI.

Harvey, D. (2013). Rebel Cities. From the right to the city to the urban revolution. Verso.

Jacobs, J. (1969). The Economy of Cities. Random House.

Leal, J. (2003). Segregación social y mercado de vivienda en las grandes ciudades. Revista Española de Sociología, (2), 57-75.

Lefebrvre, H. (1974). La Production de l'espace. Anthropos.

Lefebvre, H. (1972). La pensée marxiste et la ville. Editions Castermann.

Llobregat, A. d. (2017, 3 27). Registre de planejament urbanístic de Catalunya. Recuperado de:

http://ptop.gencat.cat/rpucportal/AppJava/cercaExpedient.do?reqCode=veureDocum ent\&codintExp=266023\&fromPage=loadAvancada $(10 / 10 / 2021)$.

Martín, A., López-Roldán, P., y Óscar, M. (2011). Movilidad ascendente de la inmigración en España. ¿Asimilación o segmentación ocupacional? Papers, 96(4), 1335-1362.

Morcuende, A. (2018). Rupturas Urbanas. Análisis de las relaciones entre la morfología urbana y la estructura social en la Barcelona contemporánea. Universidad de Barcelona.

Palomera, J., Lundsteen, M., y Martínez Veiga, U. (2014). Reproducción social y conflicto en las periferias urbanas del Estado español. In A. A. (ed.), Reproducción social y conflicto en las periferias urbanas del Estado español. Publicacions URV.

Porcel, S. (2016). Dinámicas de estructuración socioresidencial en la Barcelona metropolitana postindustrial ¿Hacia una ciudad dual o cuarteada? Universitat Autònoma de Barcelona.

Prieto, M., y Muñoz, D. (2016). L'Hospitalet: un nou districte per Barcelona. La revolta de les periferies. Barcelona: Cooperativa Idra y Observatori DESC.

Sánchez, S. J. (2018, 10 25). Manuel Domínguez, president del Centre d'Estudis de L'Hospitalet 'A l'hora de construir, el patrimoni fa nosa'. Recuperado de: https://directa.cat/a-lhora-de-construir-el-patrimoni-fa-nosa/ (10/10/2021).

Smith, N. (1979). Towards a Theory of Gentrification. A back to the City movement by capital not people. Journal of American Planning Association, (45), 538-548.

Zarlenga, M., Rius, J., y Sánchez, V. (2012). ¿Ciudad creativa y ciudad sostenible? Un análisis crítico del 'modelo Barcelona' de políticas culturales. Revista Crítica de Ciencias Sociales, (99), 31-50. 


\section{ANEXOS}

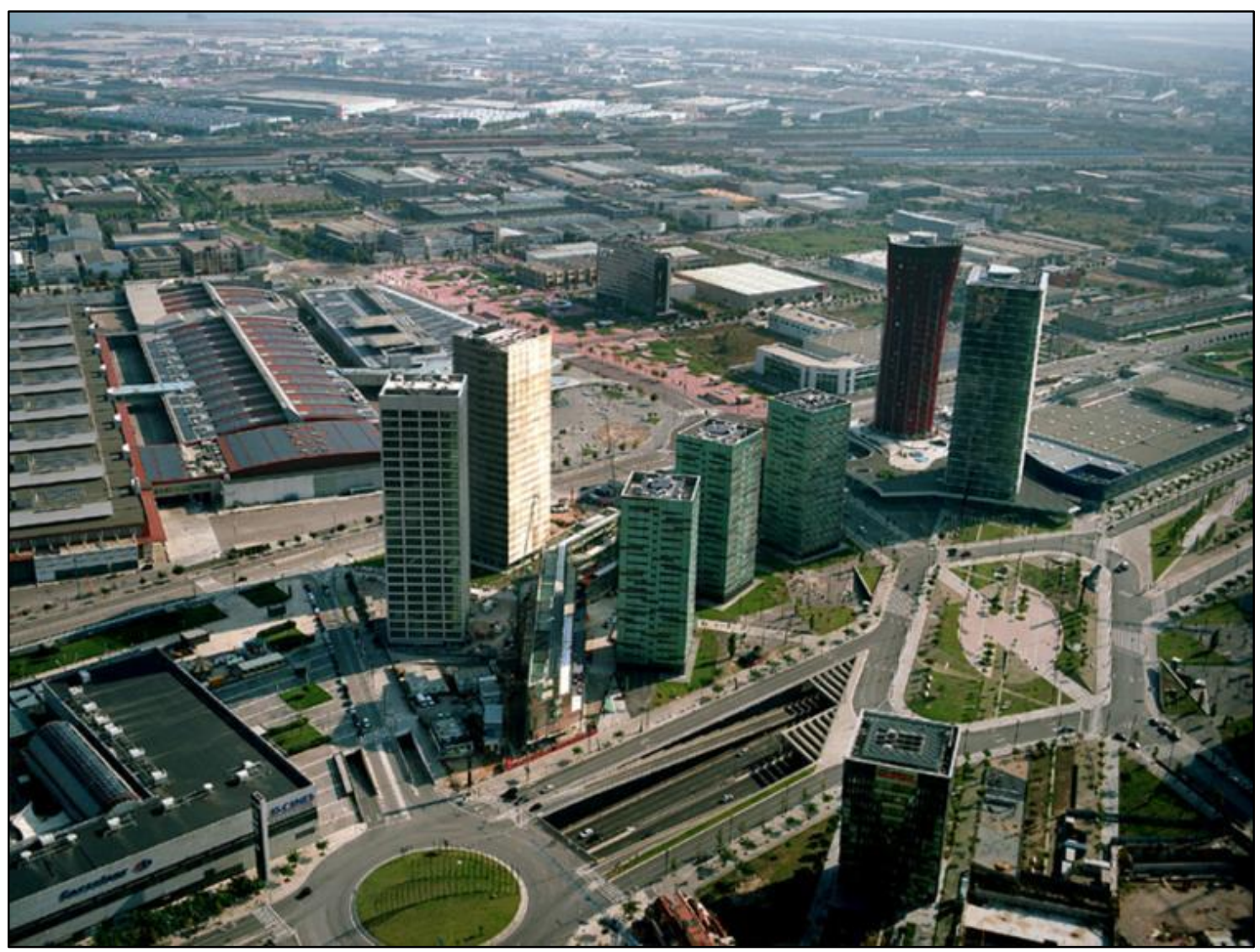

Vista de Águila de Gran Vía-Plaza de Europa/ Inbisa

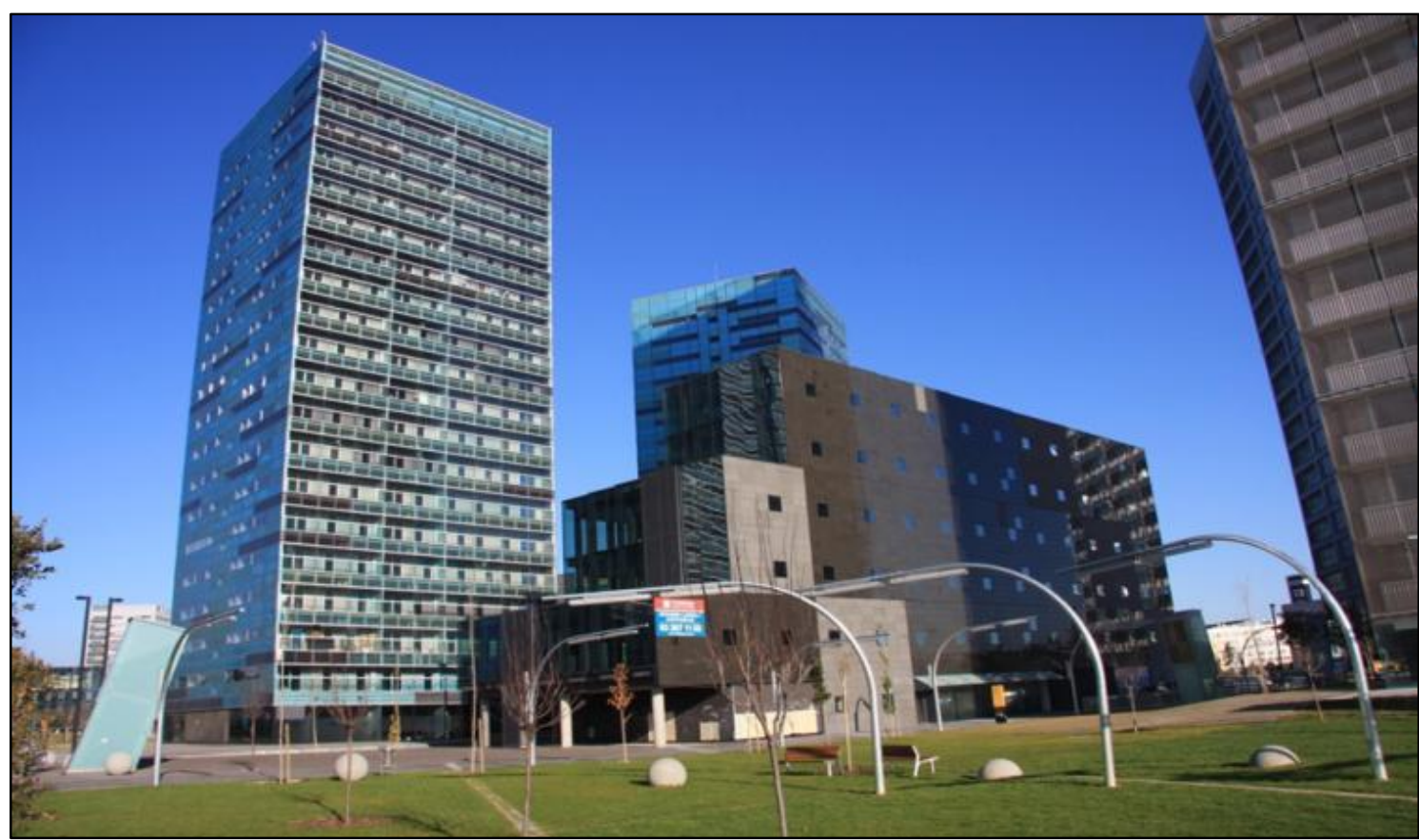

Edificios de la Plaza de Europa/ Alejandro Caamaño 


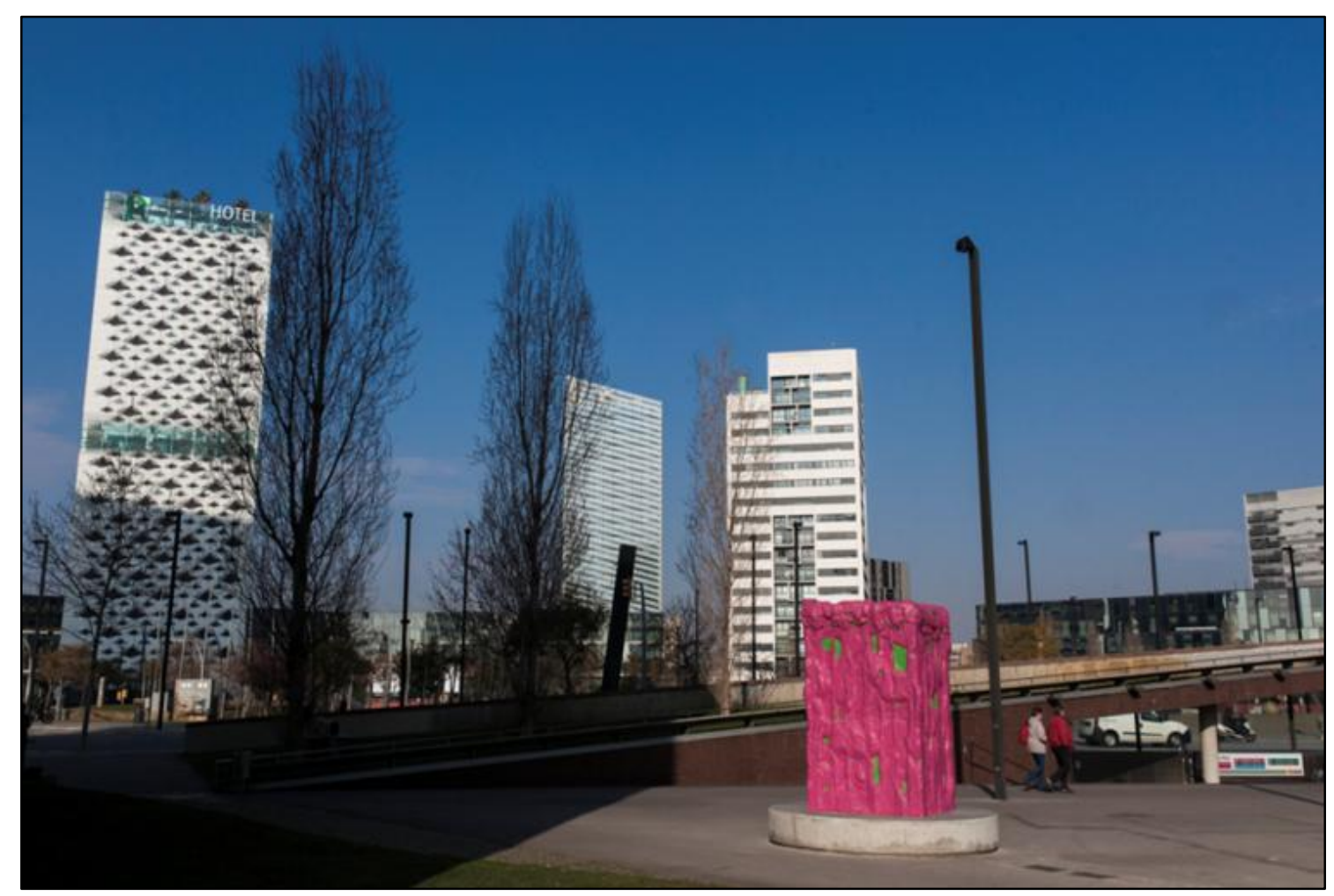

Plaza de Europa/ Alejandro Caamaño

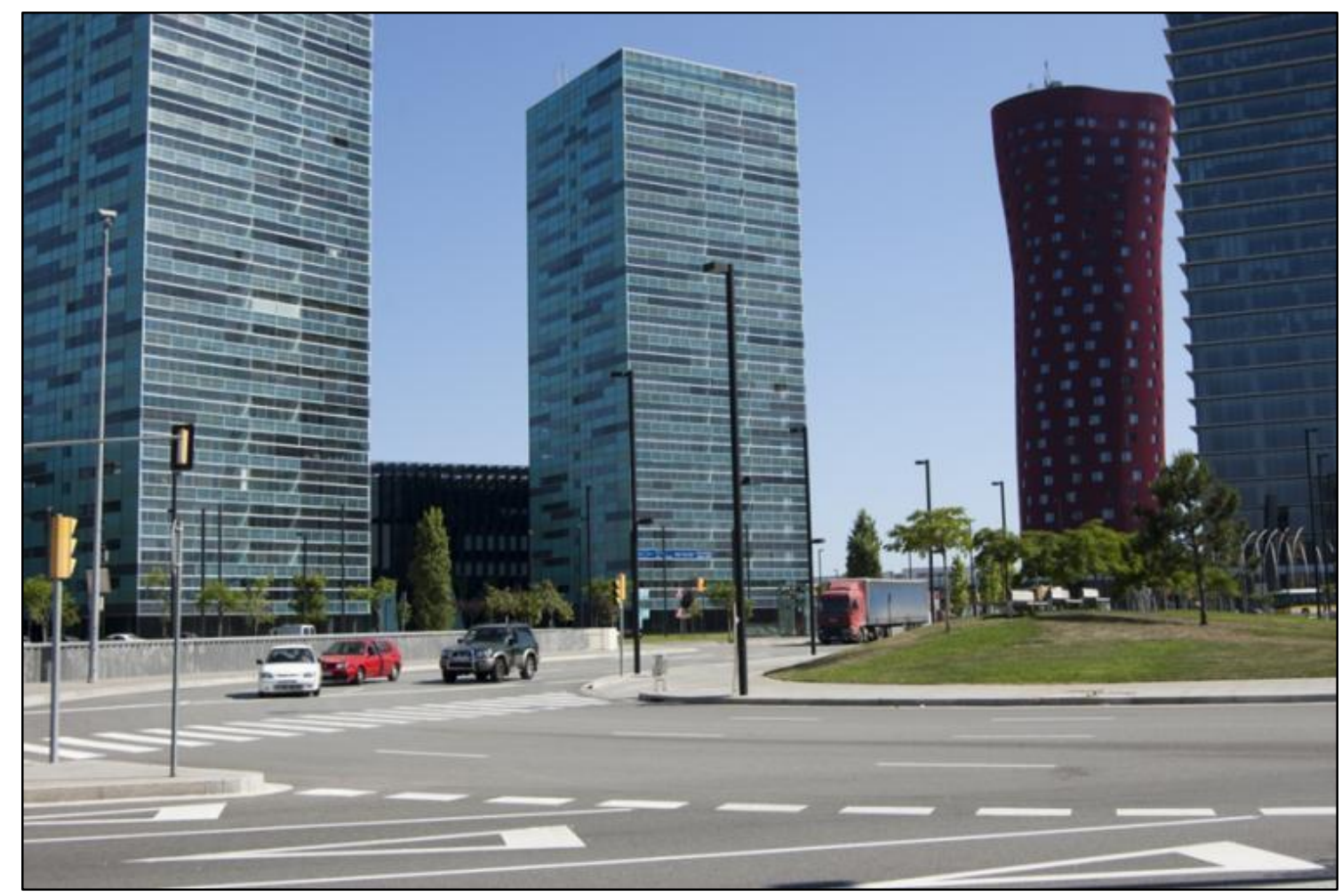

Rotonda Plaza de Europa; Hotel Porta Fira /Alejandro Caamaño 


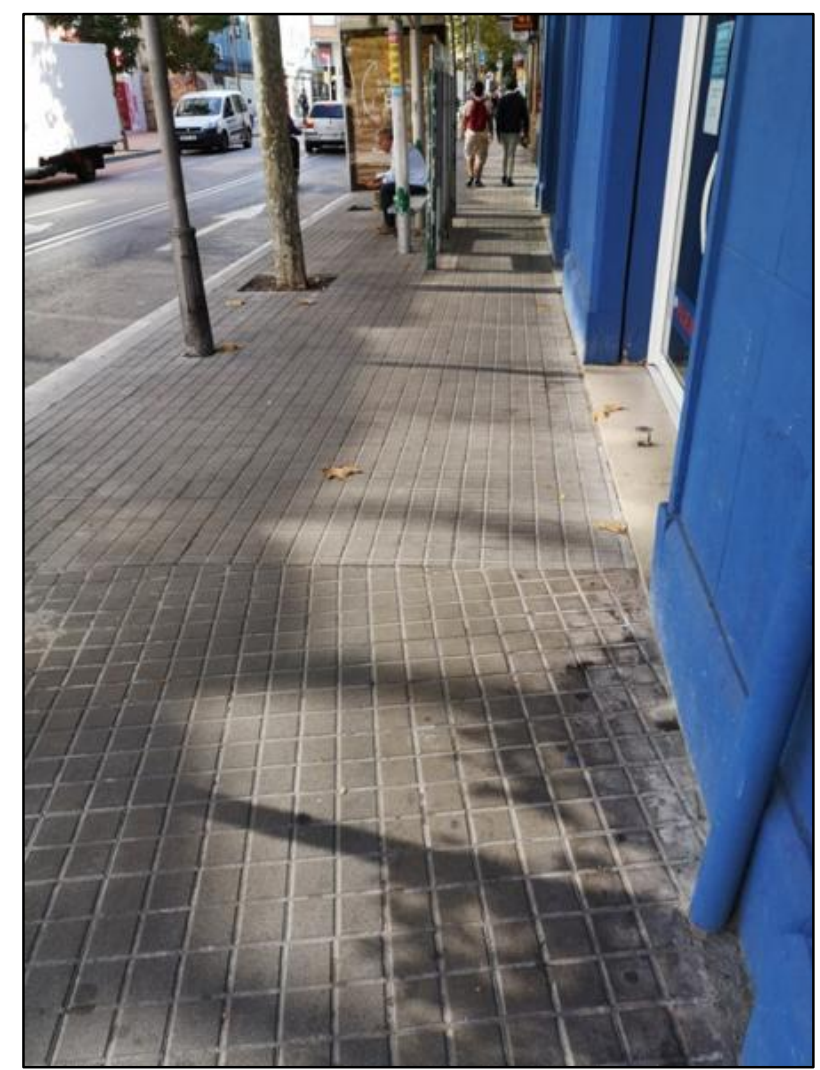

Acera antigua de la Calle Santa Eulàlia/ Alejandro Caamaño

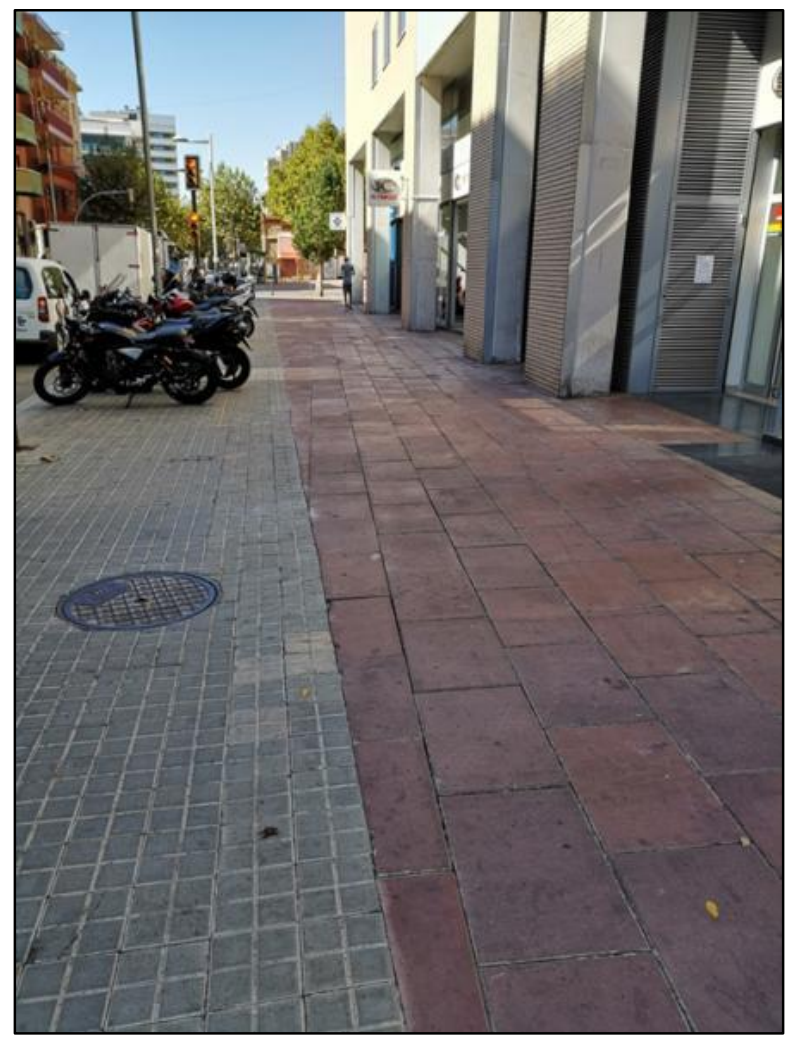

Ensanche de la acera de Santa Eulàlia Avenue/ Alejandro Caamaño 


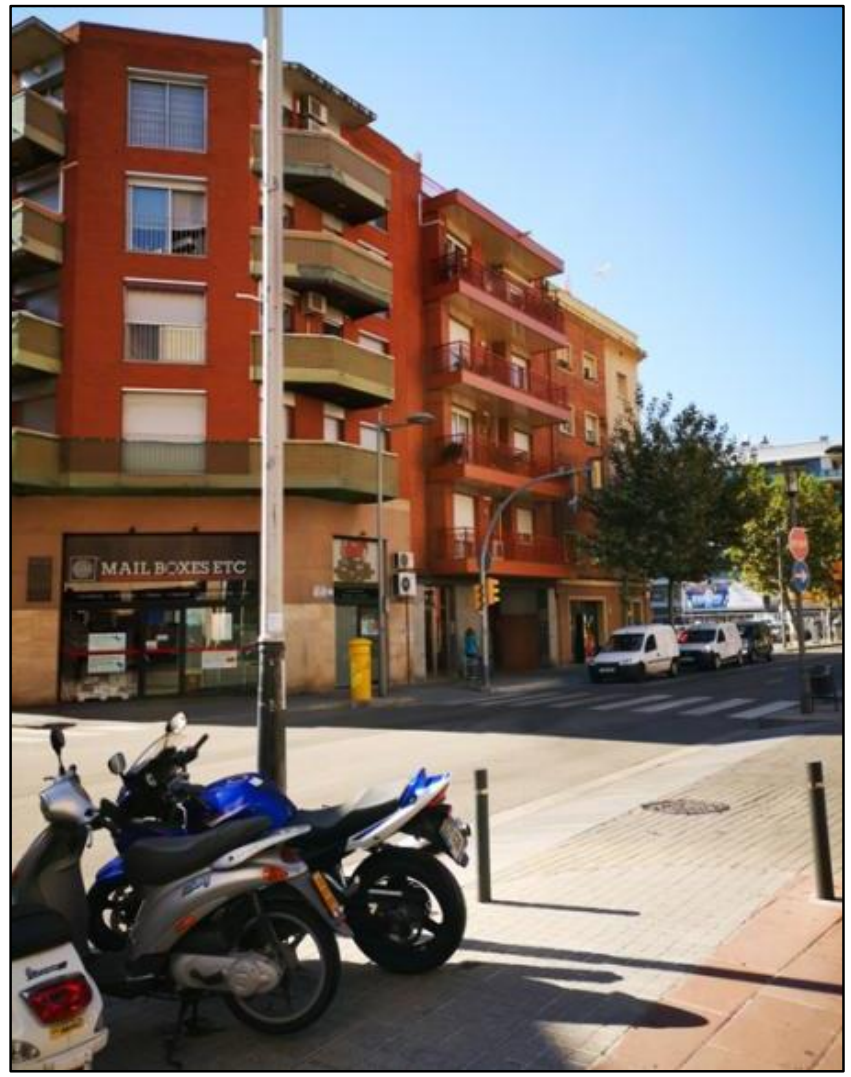

Bloques de la Calle Santa Eulàlia/ Alejandro Caamaño

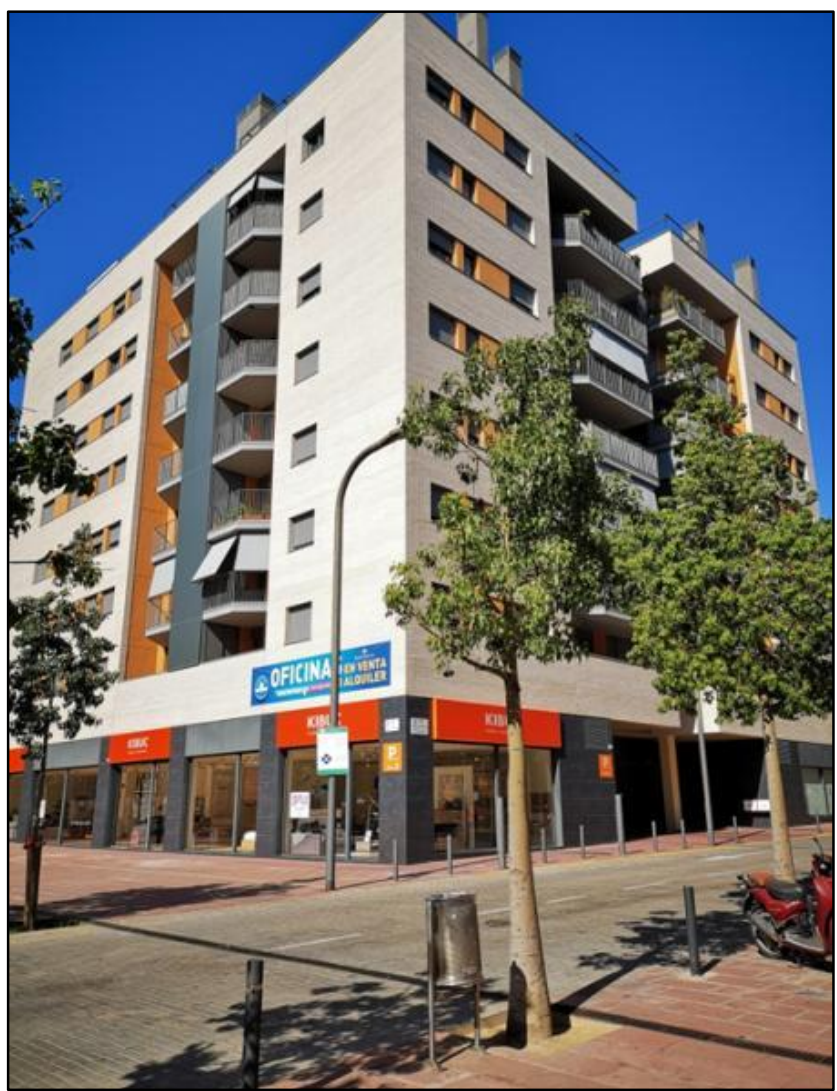

Bloque de Santa Eulàlia Avenue/ Alejandro Caamaño 


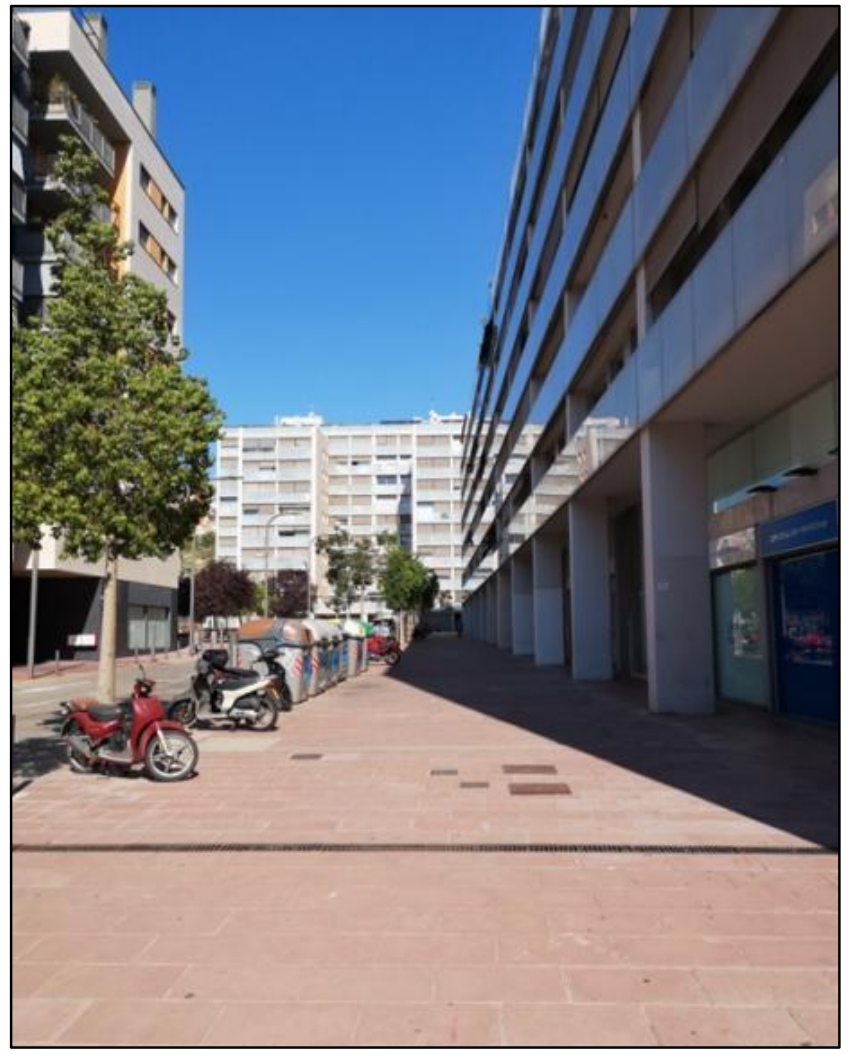

Acceso a la zona interior de bloques de Santa Eulàlia Avenue/ Alejandro Caamaño

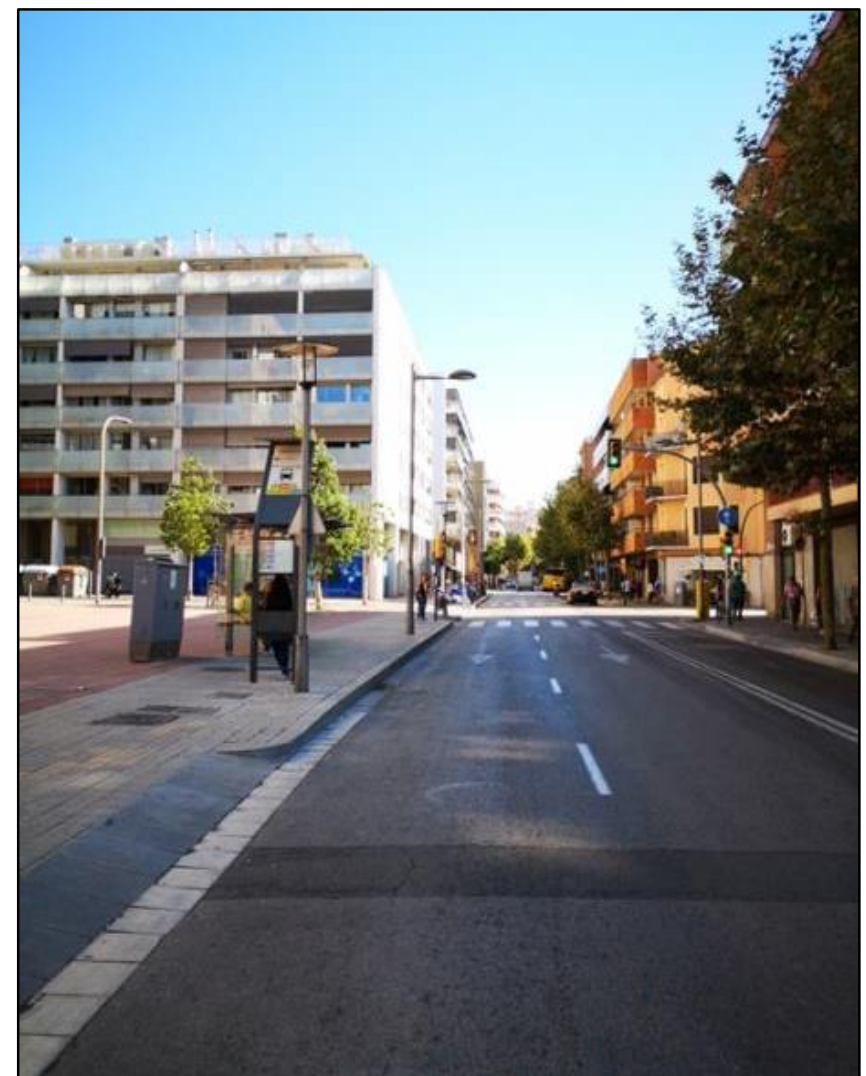

Santa Eulàlia en dos velocidades/ Alejandro Caamaño 


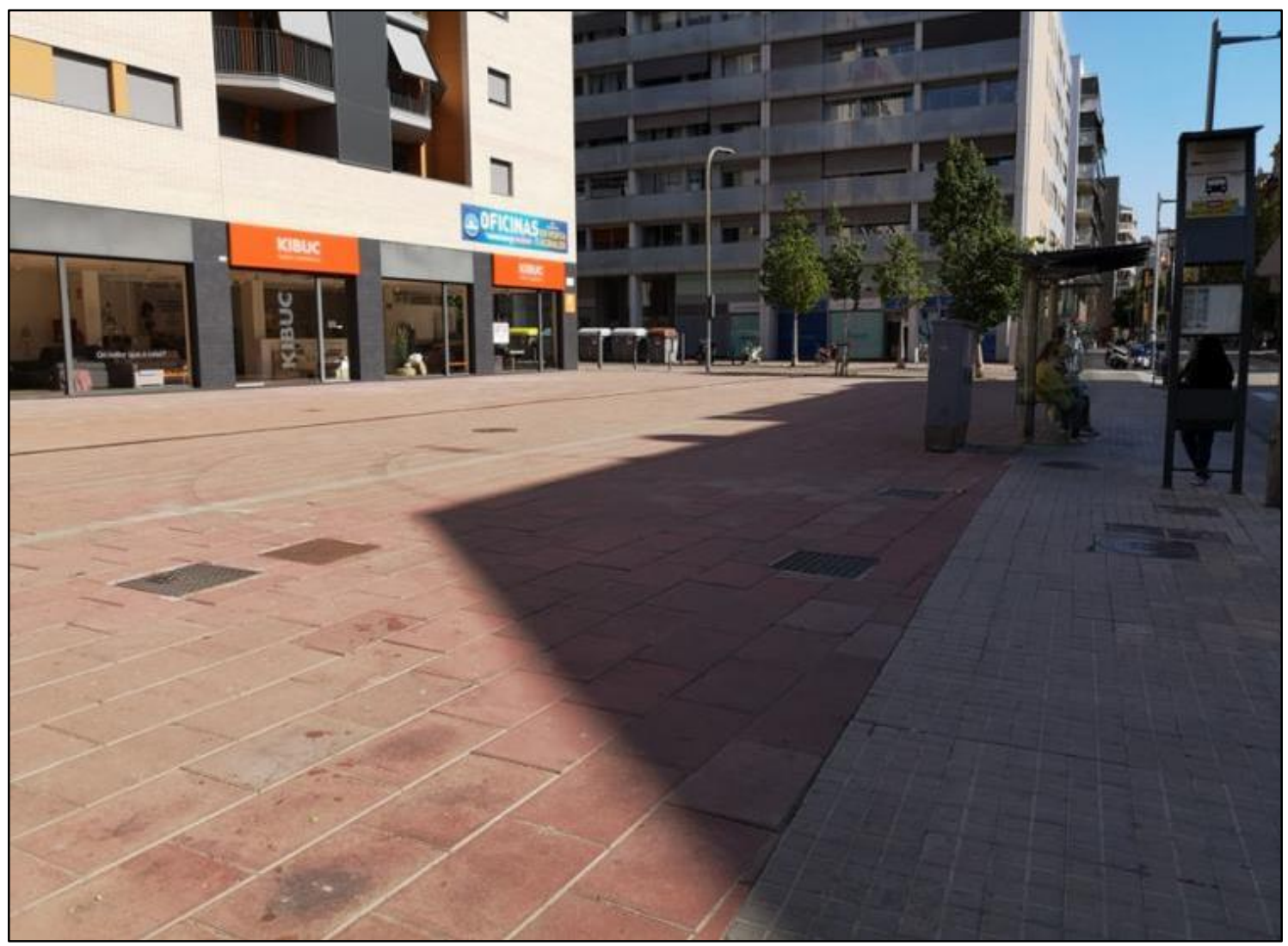

Acera de Santa Eulàlia Avenue/ Alejandro Caamaño

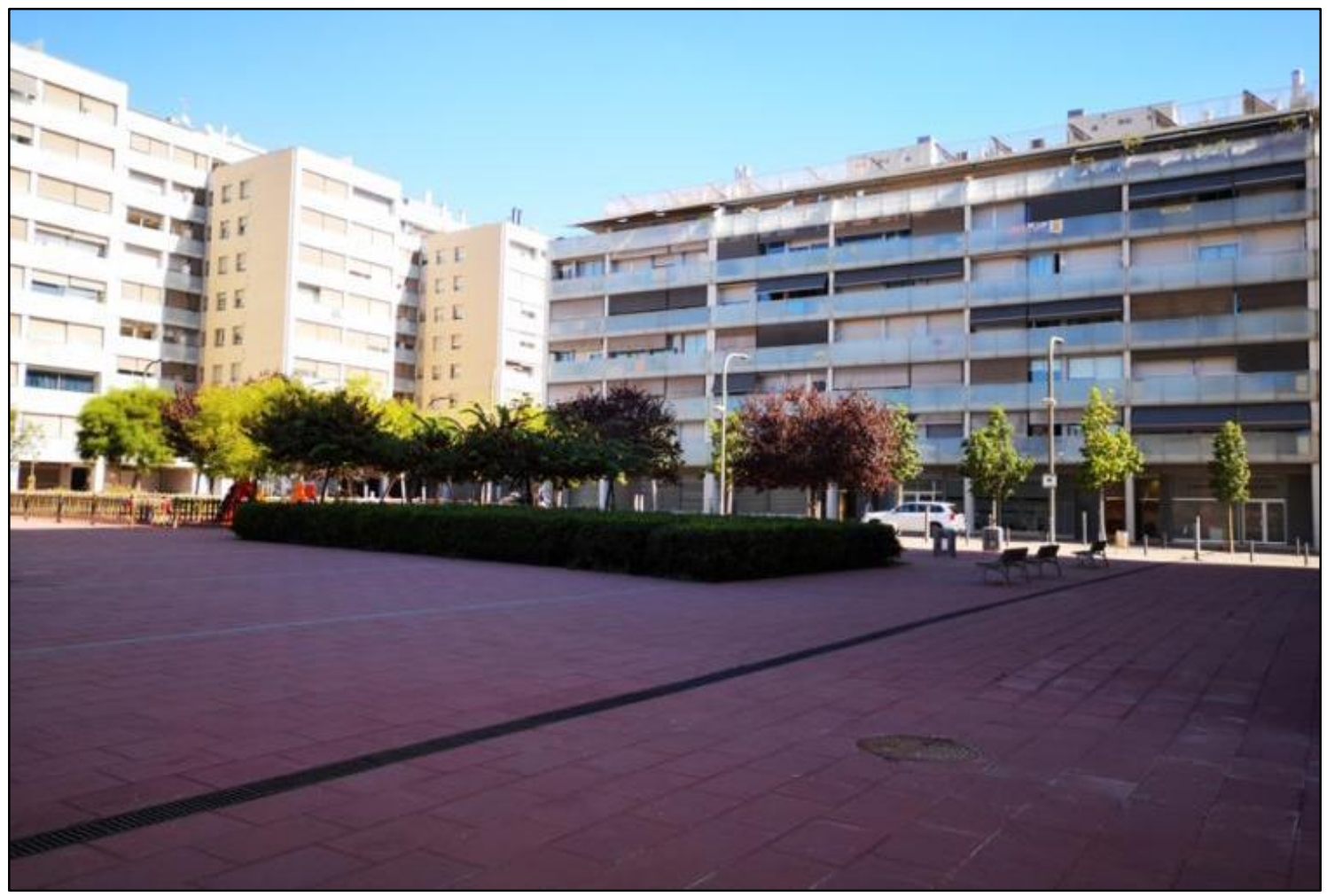

Parque interior de Santa Eulàlia Avenue con estructura residencial/ Alejandro Caamaño 


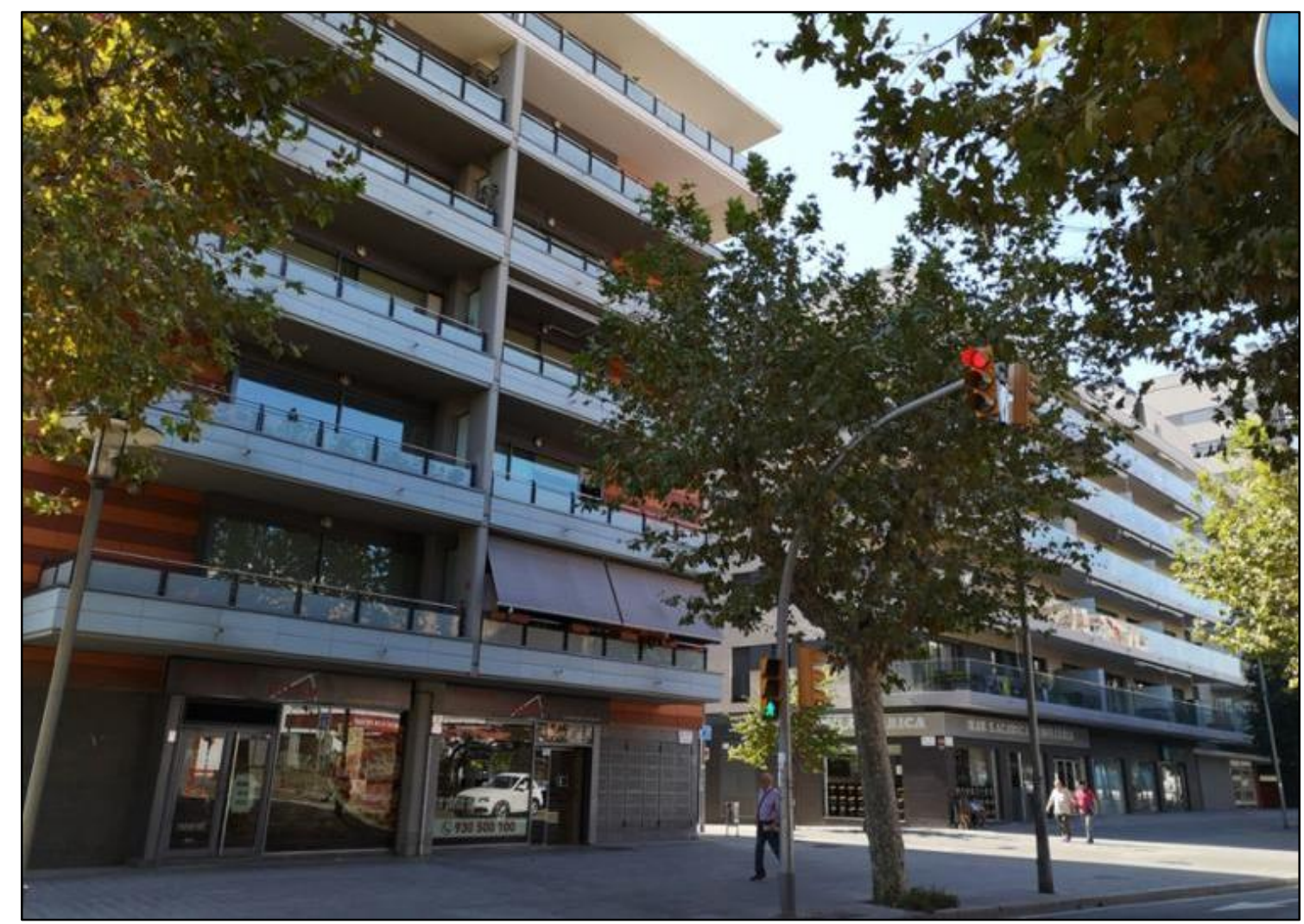

Bloques de Santa Eulàlia Avenue

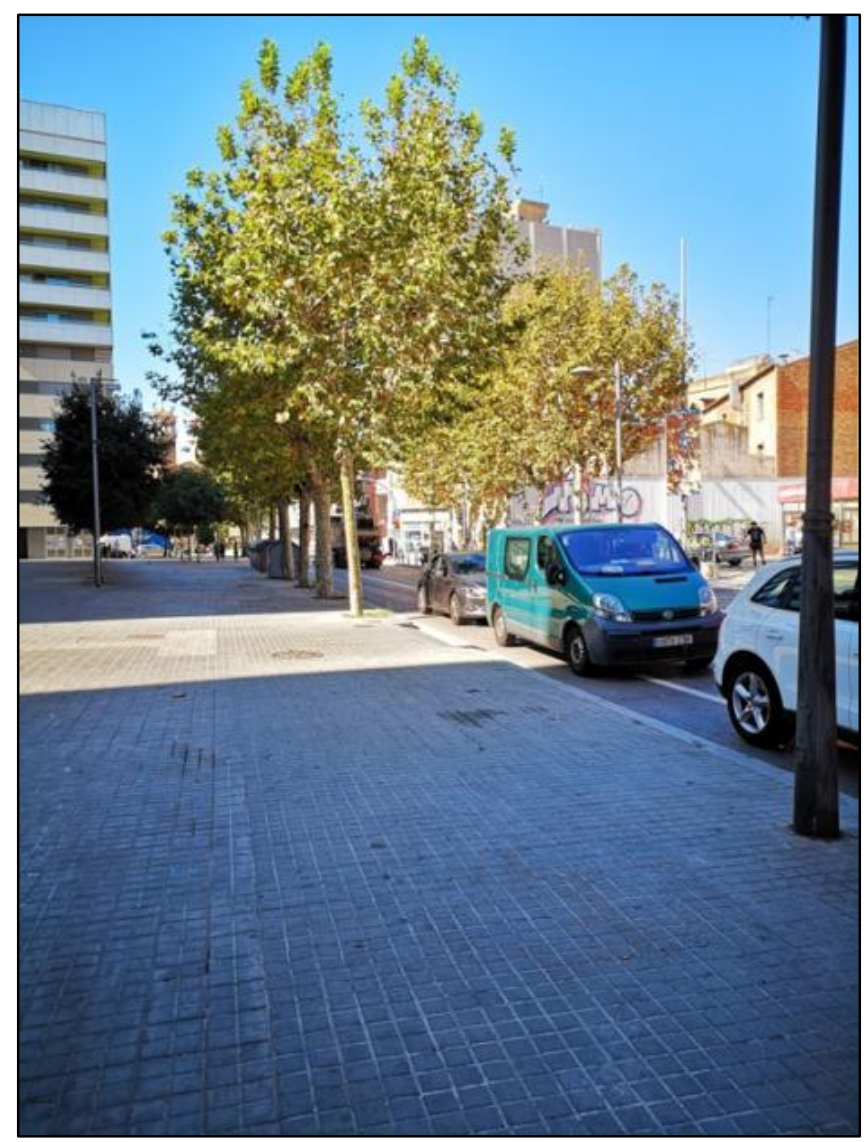

Ensanche de acera Santa Eulàlia Avenue/ Alejandro Caamaño 


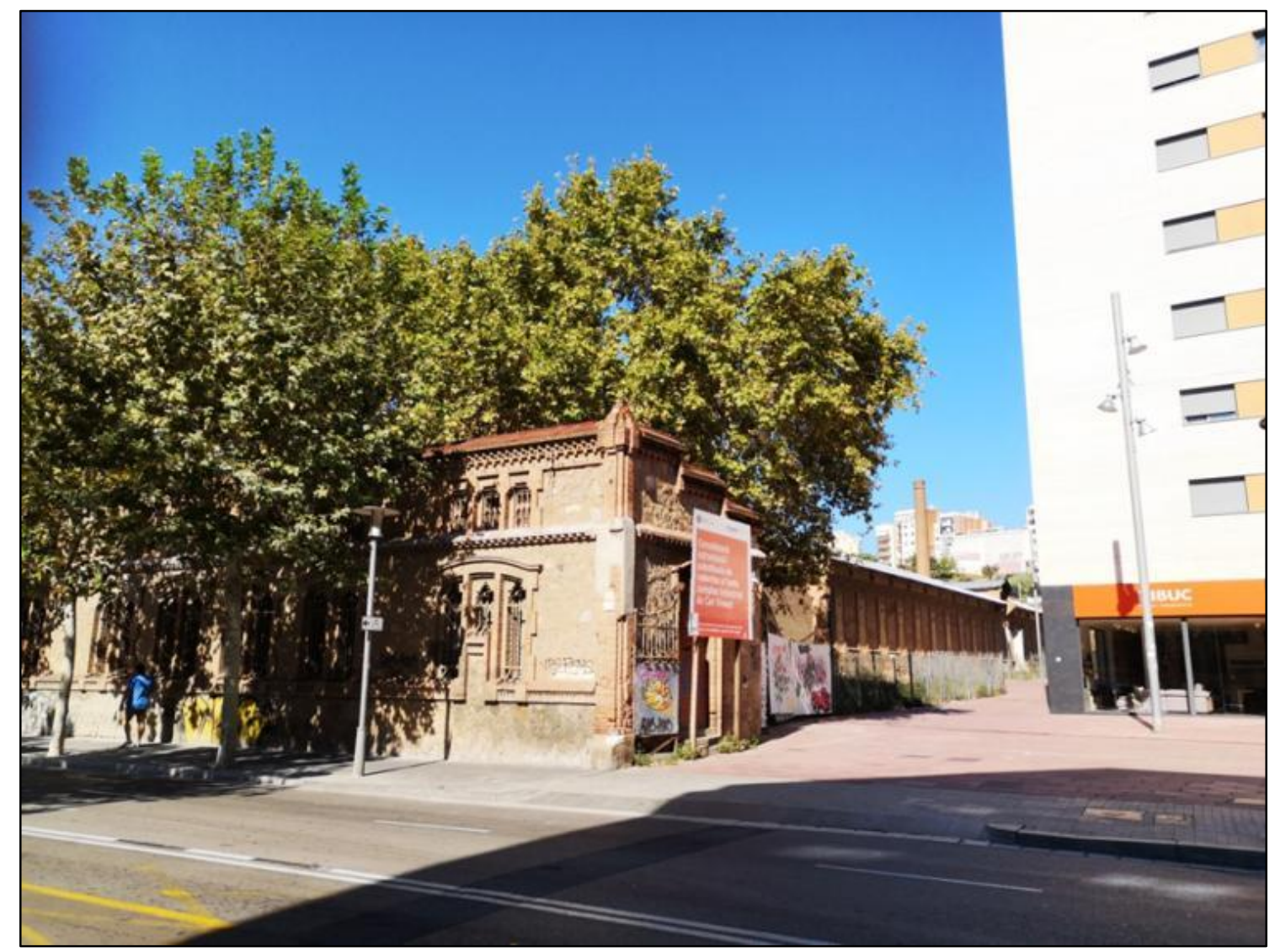

Can Trinxet/ Alejandro Caamaño

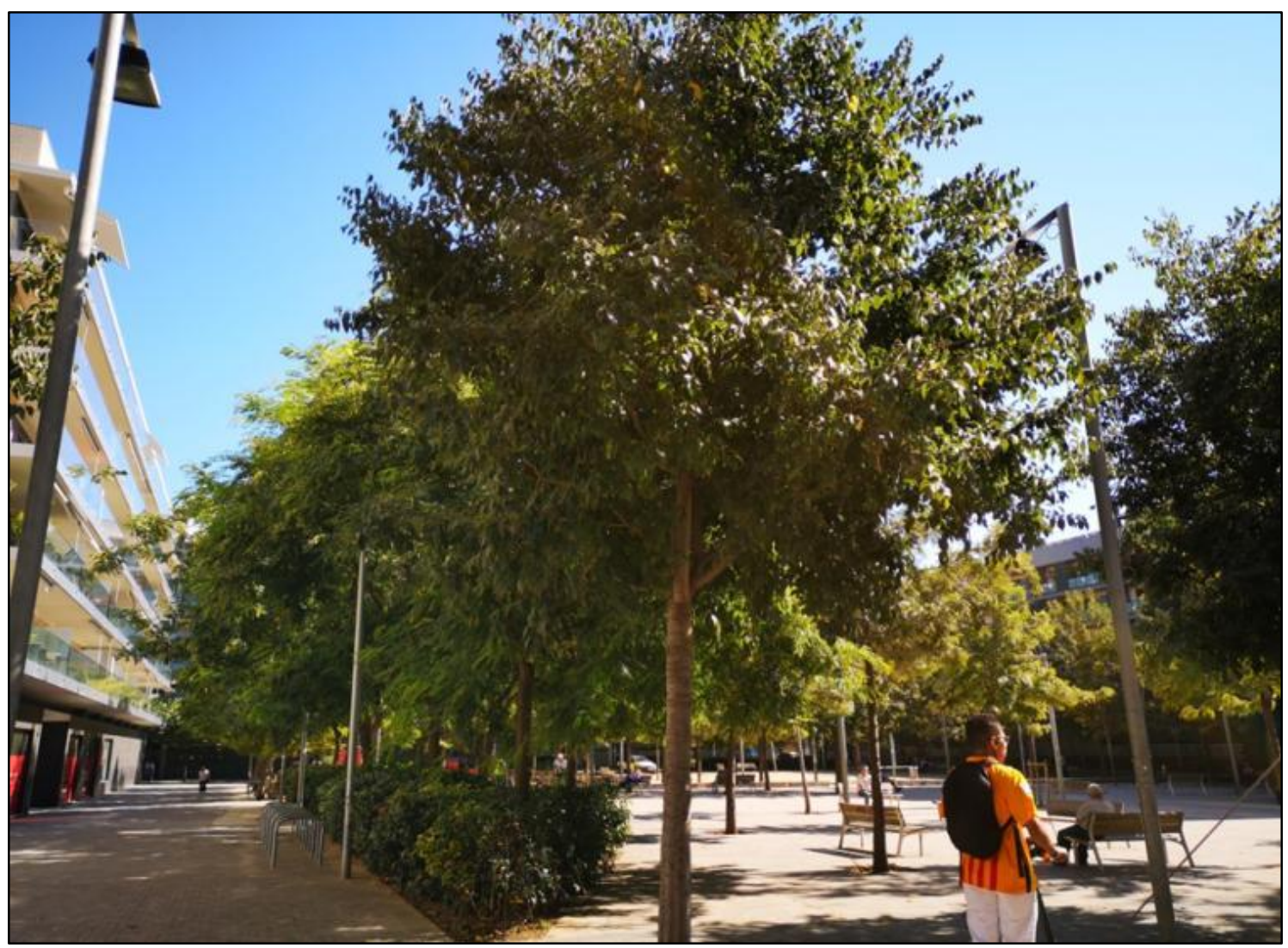

Parque de la plaza UNICEF/ Alejandro Caamaño 


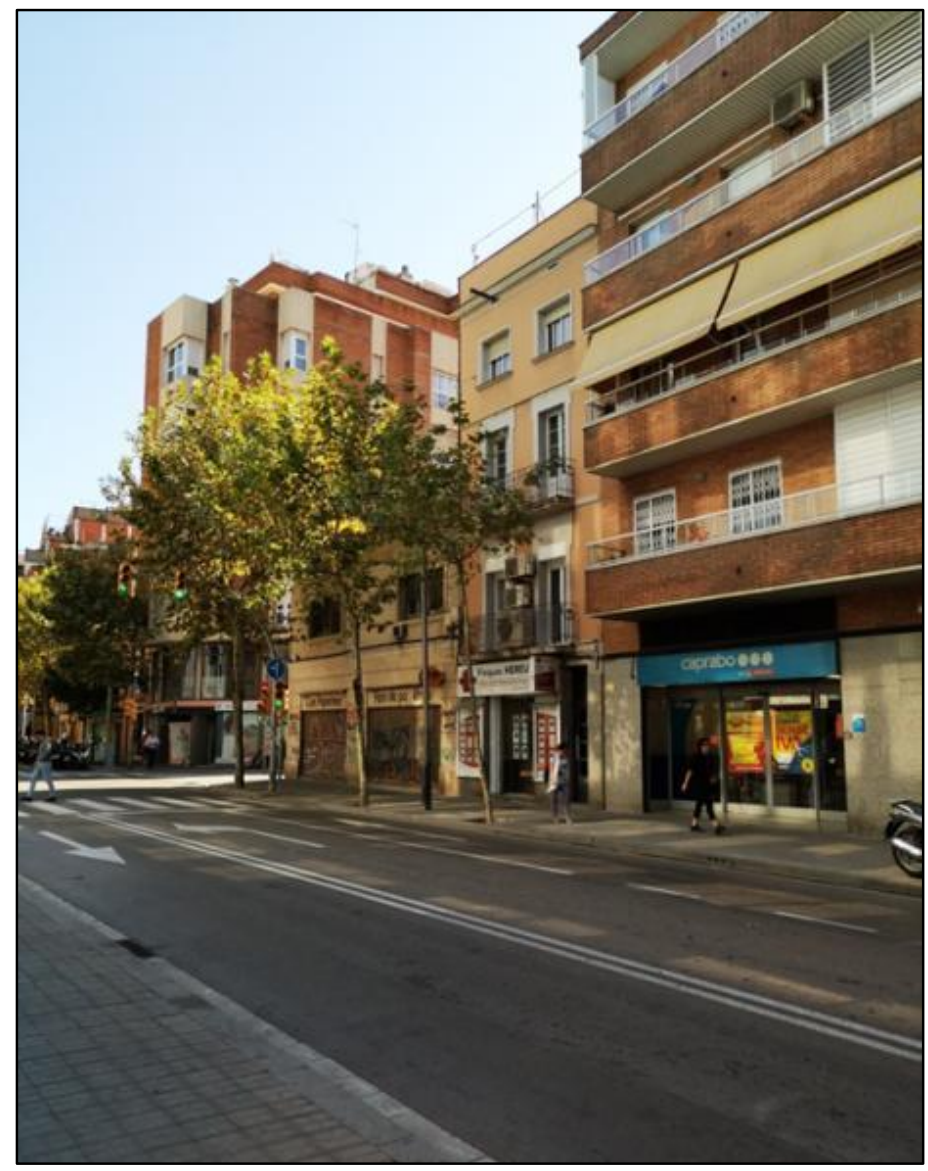

Calle Santa Eulàlia/ Alejandro Caamaño

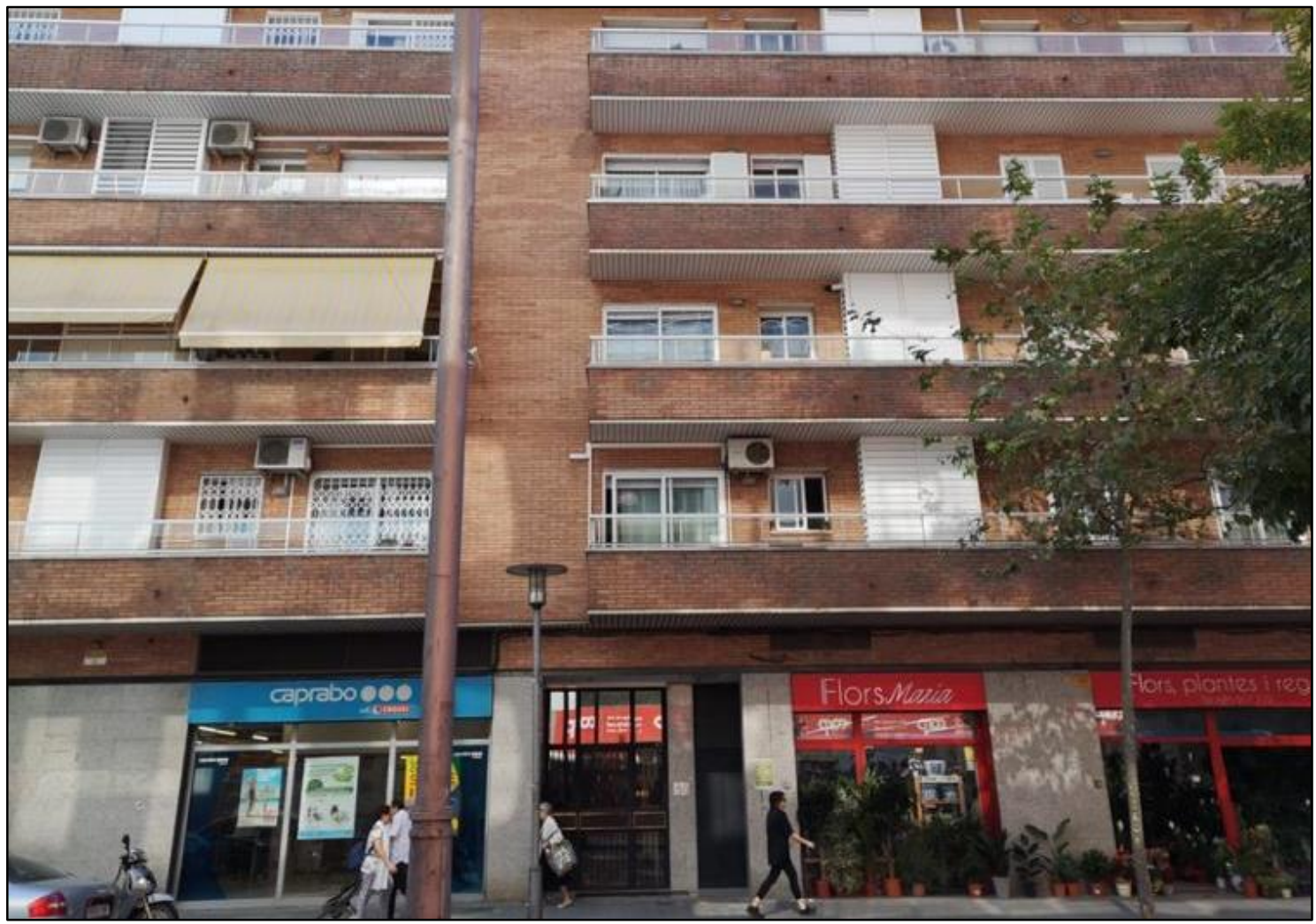

Bloques de la Calle Santa Eulàlia/ Alejandro Caamaño 


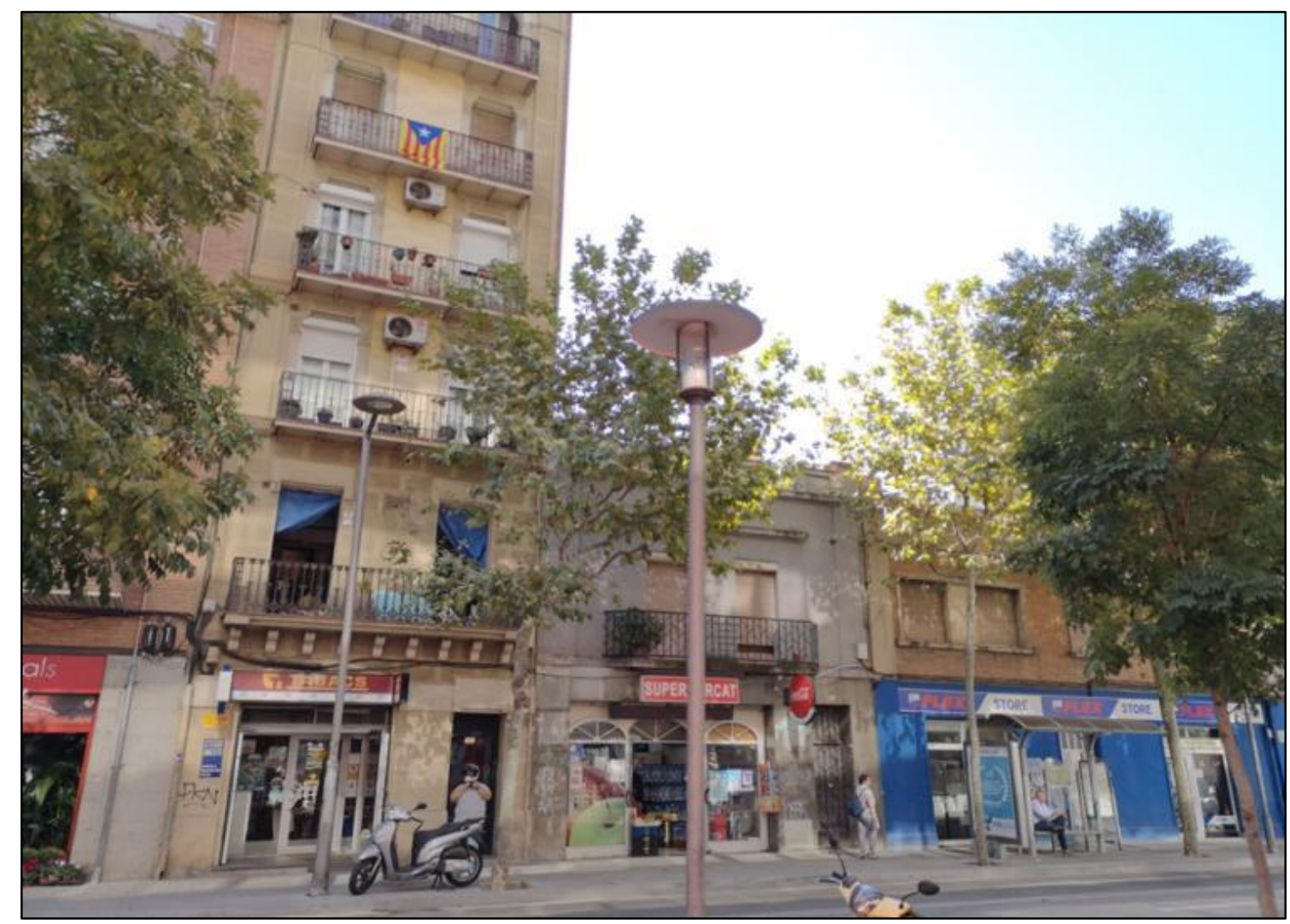

Bloques de edificación antigua en calle Santa Eulàlia/ Alejandro Caamaño

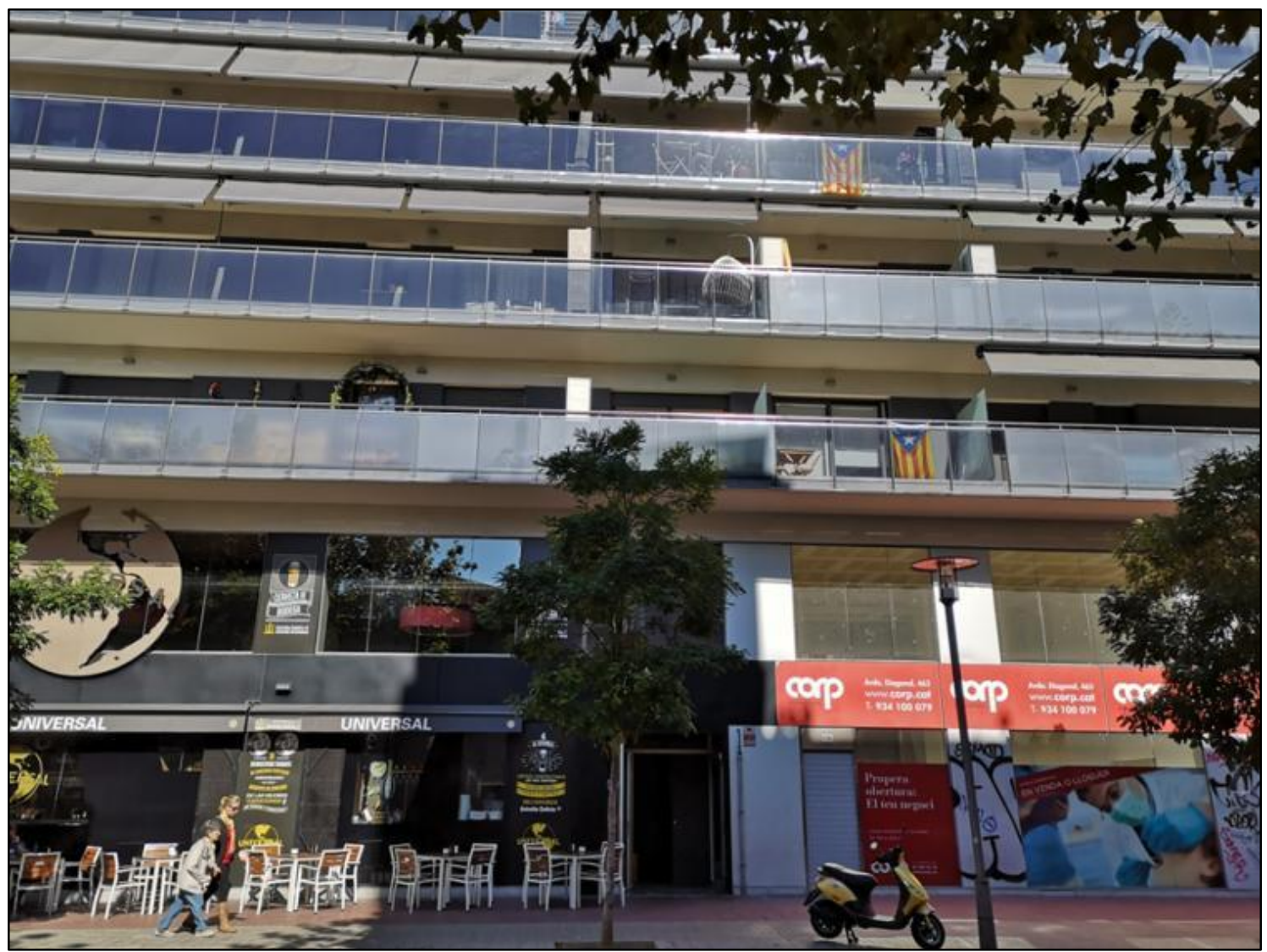

Bloque construido por Corp de Santa Eulàlia Avenue/ Alejandro Caamaño 


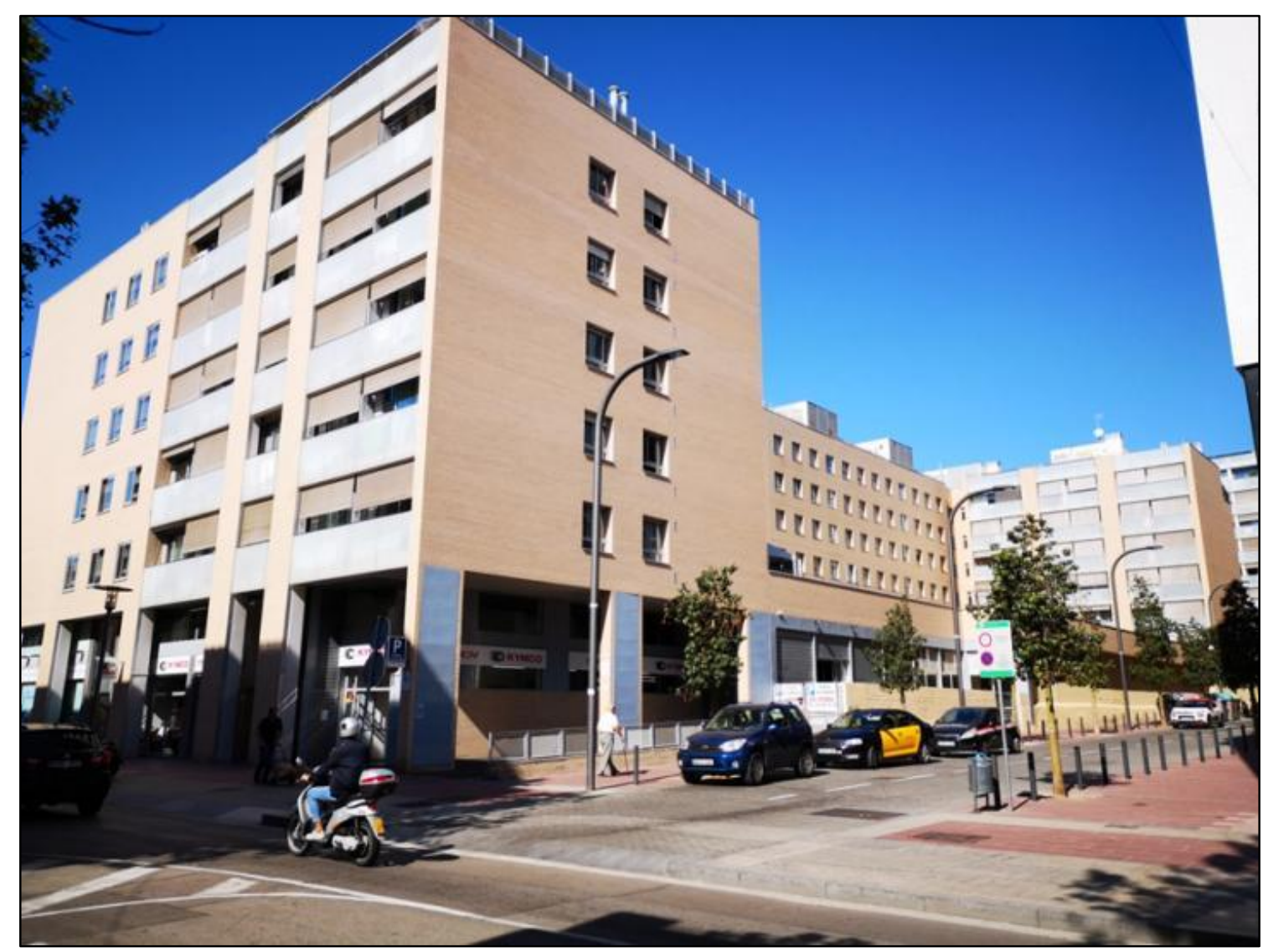

Bloque Santa Eulàlia Avenue/ Alejandro Caamaño

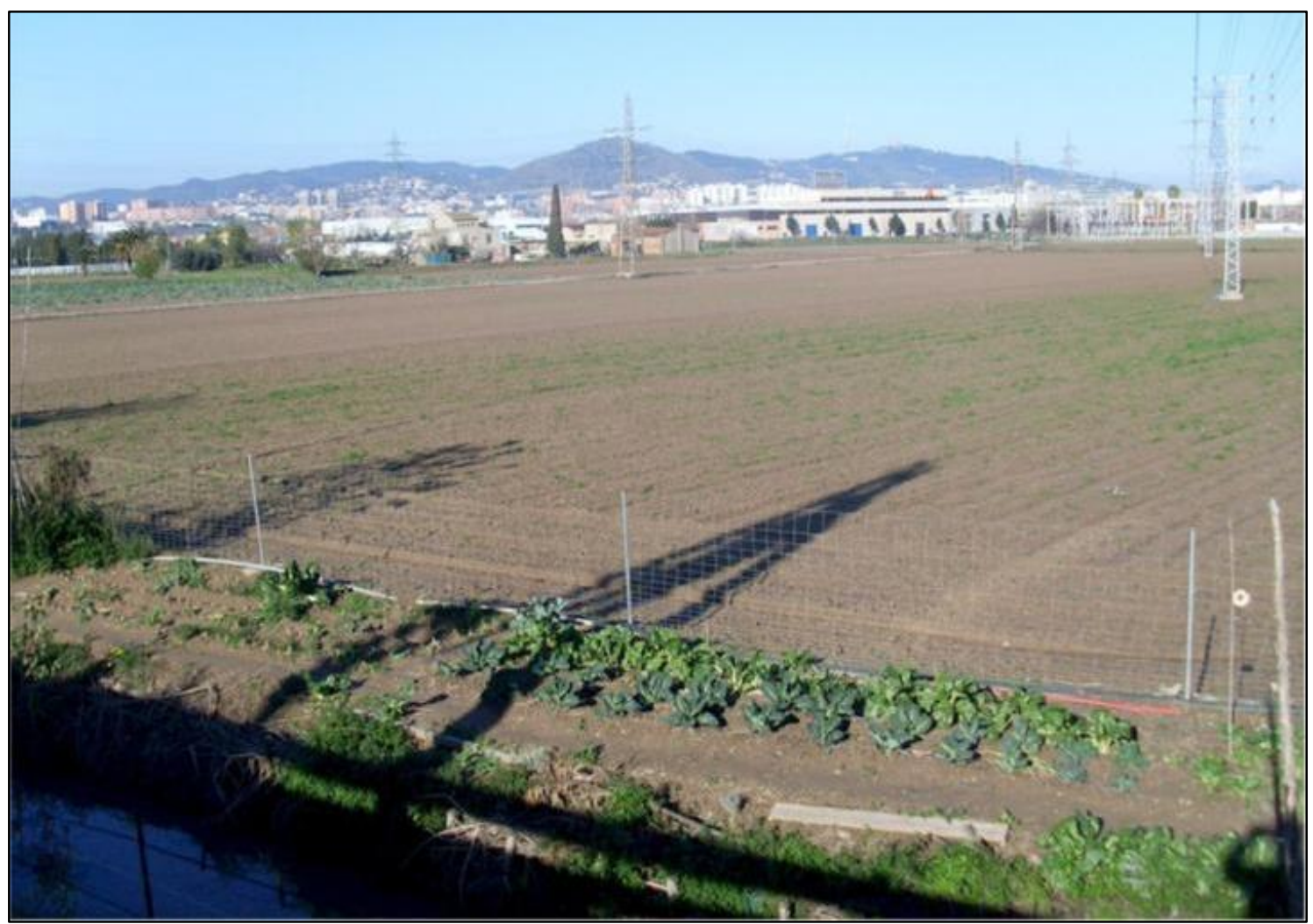

Huertos de Cal Trabal/ Alejandro Caamaño 


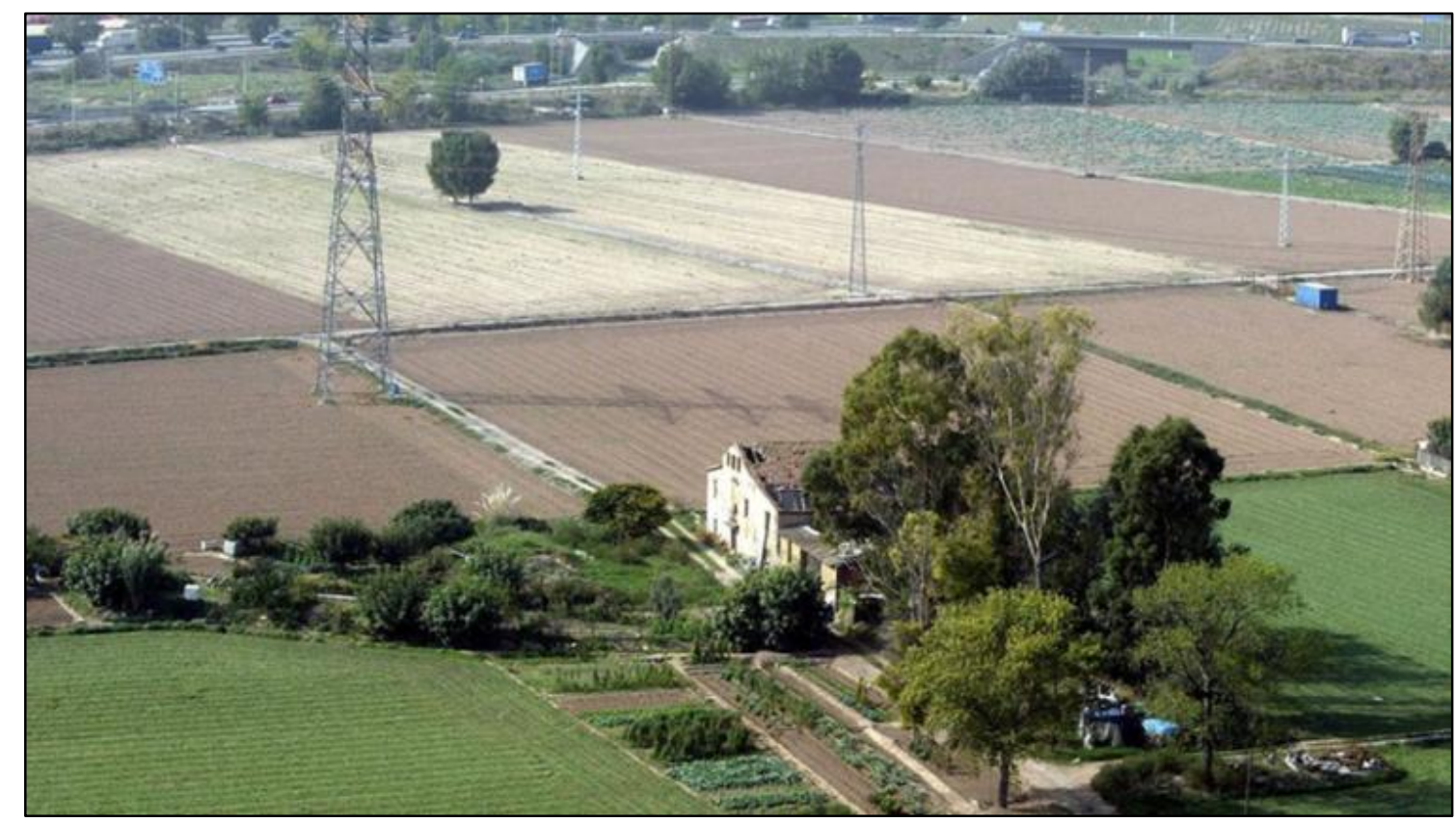

Una de les tres masías del sector agrario de Cal Trabal/Juanma Ramos

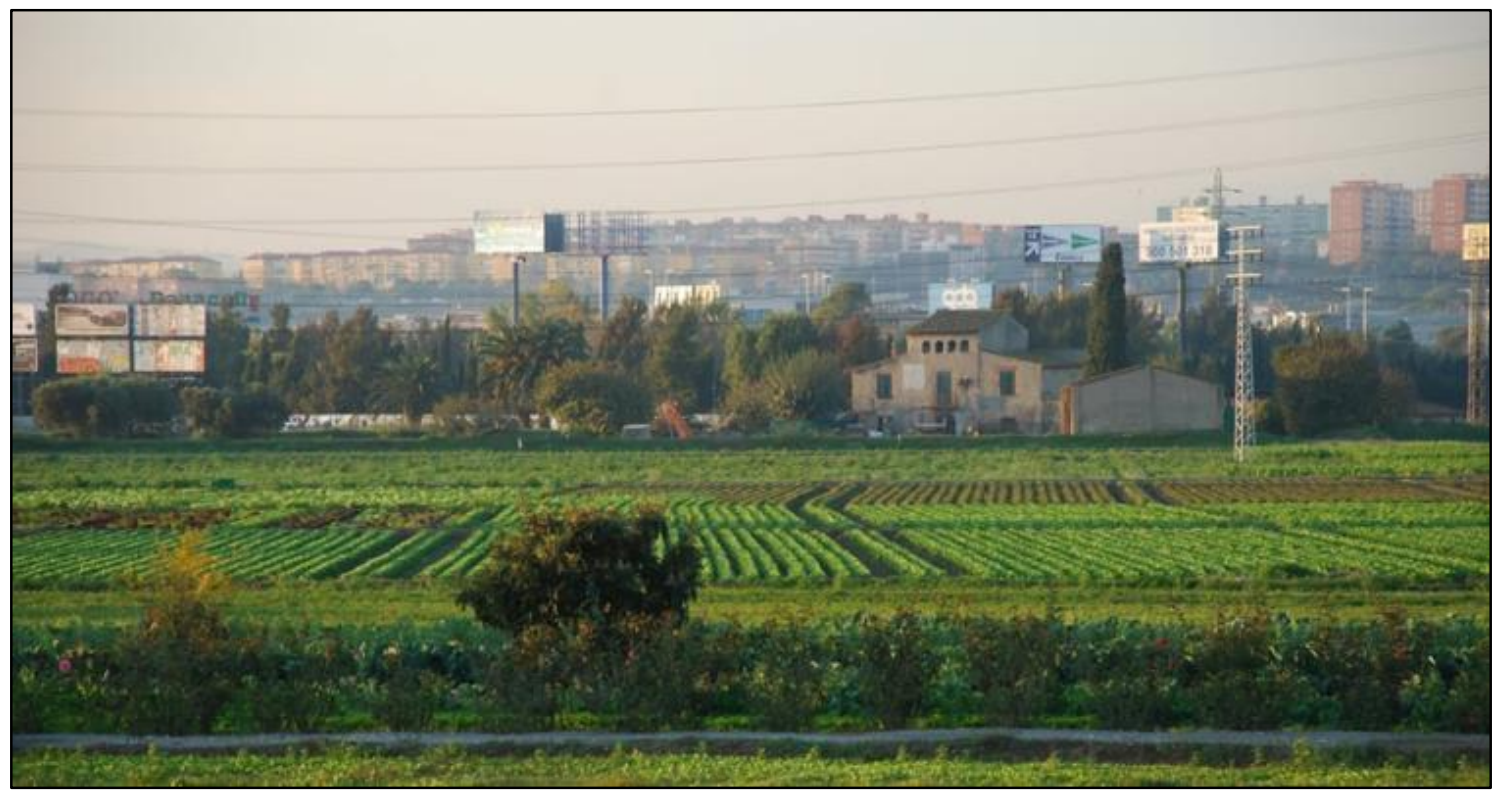

Panorámica Cal Trabal/ Alejandro Caamaño

\section{1 . UNIVERSITAT JAUMEI}

Institut Interuniversitari de Desenvolupament Local 